\title{
TÉCNICAS PEDAGÓGICAS
}

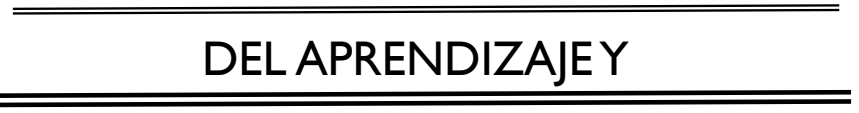

APLICACIÓN DE DESTREZAS

Yenny A. Zambrano Villegas

Martha L. Mendoza Navarrete

Marcos T. Zambrano Zambrano

Fredy C. Zambrano Velásquez

Carmen D. Andrade Zambrano

Limber L. Rivas Cedeño 
TÉCNICAS PEDAGÓGICAS DEL APRENDIZAJE Y APLICACIÓN

DE DESTREZAS

C) Autores

Yenny A. Zambrano-Villegas

Docente de la Universidad Laica Eloy Alfaro de Manabí

Martha L. Mendoza-Navarrete

Docente de la Universidad Laica Eloy Alfaro de Manabí

Marcos T. Zambrano-Zambrano

Docente de la Universidad Laica Eloy Alfaro de Manabí

Fredy C. Zambrano-Velásquez

Docente de la Universidad Laica Eloy Alfaro de Manabí

Carmen D. Andrade-Zambrano

Docente de la Universidad Laica Eloy Alfaro de Manabí

Limber L. Rivas-Cedeño

Docente de la Universidad Laica Eloy Alfaro de Manabí 
Casa Editora del Polo - CASEDELPO CIA. LTDA.

Departamento de Edición

\section{Editado y distribuido por:}

(c) Casa Editora del Polo

Sello Editorial: 978-9942-816

Manta, Manabí, Ecuador. 2019

Teléfono: (05) 6051775 / 0991871420

https://www.casedelpo.com/

ISBN: 978-9942-980-03-8

DOI:

(C) Primera edición

(C) Agosto - 2019

Impreso en Ecuador

Revisión, Ortografía y Redacción:

Dra. Tibisay Milene Lamus-García

Diseño de Portada:

Michael Josué Suárez-Espinar

\section{Diagramación:}

Ing. Edwin Alejandro Delgado-Veliz

\section{Director Editorial:}

PhD. Julio Juvenal Aldana -Zavala

Todos los libros publicados por la Casa Editora del Polo, son sometidos previamente a un proceso de evaluación realizado por árbitros calificados.

Este es un libro digital y físico, destinado únicamente al uso personal y colectivo en trabajos académicos de investigación, docencia y difusión del Conocimiento, donde se debe brindar crédito de manera adecuada a los autores.

(c) Reservados todos los derechos. Queda estrictamente prohibida, sin la autorización expresa de los autores, bajo las sanciones establecidas en las leyes, la reproducción parcial o total de este contenido, por cualquier medio o procedimiento.parcial o total de este contenido, por cualquier medio o procedimiento. 
Comité Científico Académico

Dr. Lucio Noriero-Escalante

Universidad Autónoma de Chapingo, México

Dra. Yorkanda Masó-Dominico

Instituto Tecnológico de la Construcción, México

Dr. Juan Pedro Machado-Castillo

Universidad de Granma, Bayamo. M.N. Cuba

Dra. Fanny Miriam Sanabria-Boudri

Universidad Nacional Enrique Guzmán y Valle, Perú

Dra. Jennifer Quintero-Medina

Universidad Privada Dr. Rafael Belloso Chacín, Venezuela

Dr. Félix Colina-Ysea

Universidad SISE. Lima, Perú

Dr. Reinaldo Velasco

Universidad Bolivariana de Venezuela, Venezuela

Dra. Lenys Piña-Ferrer

Universidad Rafael Belloso Chacín, Maracaibo, Venezuela

Dr. José Javier Nuvaez-Castillo

Universidad Cooperativa de Colombia, Santa Marta, Colombia 
La Casa Editora del Polo, hace constar que este libro proviene de una investigación realizada por los autores, siendo sometido a un arbitraje bajo el sistema de doble ciego (peer review), de contenido y forma por jurados especialistas. Además, se realizó una revisión del enfoque, paradigma y método investigativo; desde la matriz epistémica asumida por los autores, aplicándose las normas APA, Sexta Edición, proceso de anti plagio en línea Plagiarisma, garantizándose así la cientificidad de la obra.

\section{Comité Editorial}

Abg. Néstor D. Suárez-Montes

\section{Casa Editora del Polo (CASEDELPO)}

Dra. Juana Cecilia-Ojeda

Universidad del Zulia, Maracaibo, Venezuela

Dra. Maritza Berenguer-Gouarnaluses

Universidad Santiago de Cuba, Santiago de Cuba, Cuba

Dr. Víctor Reinaldo Jama-Zambrano

Universidad Laica Eloy Alfaro de Manabí, Ext. Chone 


\section{CONTENIDO}

PRÓLOGO

PREÁMBULO

INTRODUCCIÓN

\section{CAPÍTULO I}

REFLEXIÓN INICIAL NECESARIA COMO PUNTO DE PARTIDA PARA LA ELABORACION DE TECNICAS PEDAGOGICAS Y EL

DESARROLLO DE DESTREZAS

1. Algunas aproximaciones teóricas sobre las categorías en estudio

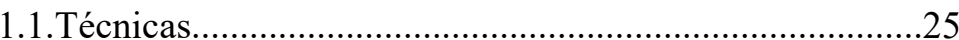

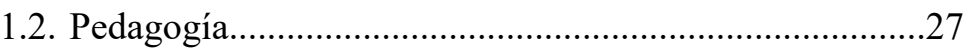

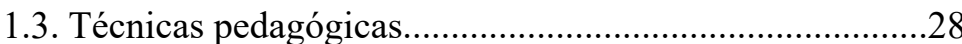

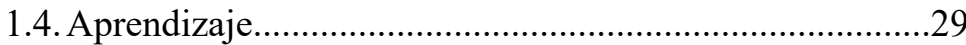

1.5.Algunos modelos o teorías sobre el aprendizaje...............30

1.5.1. Teoría Conductista.................................................3

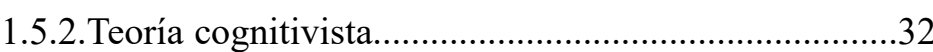

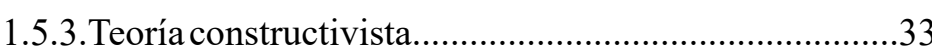

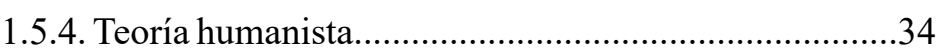

1.5.5. Teoría de la asimilación y acomodación.....................35

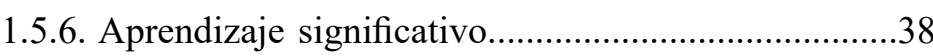

1.5.7. Interpretación socio-histórico-cultural del aprendizaje.

1.6. Destrezas para el aprendizaje pedagógico. 
1.7. Los estilos de aprendizaje y su relación con las destrezas

1.7.1. El Modelo de los Cuadrantes Cerebrales de

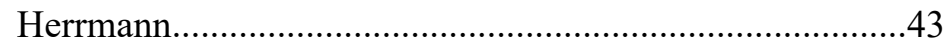

1.7.2. Modelo de Felder y Silverman ......................................45

1.7.3. Modelo de Kolb.........................................................48

1.7.4.Modelo de la Programación Neurolingüística de

Bandler y Grinder..

1.8. Técnicas de aprendizaje como paradigma educativo

en el desarrollo de destrezas.

\section{CAPÍTULO II}

LAS TECNICAS DE APRENDIZAJE EN LA

PLANIFICACIÓN PEDAGÓGICA..

2.1. Etapas Organizativas para la planificación. . .56

2.2. Principios de la Planificación...........................................58

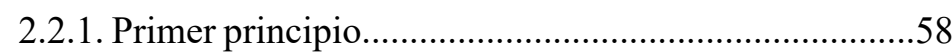

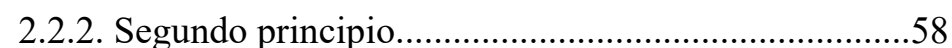

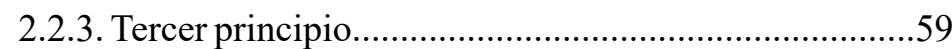

2.4. Delineando un Instrumento adecuado................................63

2.5. ¿Qué hacer si la planificación no arroja los resultados deseados?.

\section{CAPÍTULO III}

\section{DEL DIAGNOSTICO PEDAGOGICO A LA} ACCION PEDAGOGICA.

3.1. Tipos de Diagnostico.............................................................

3.2. Objetivos del diagnóstico pedagógico.................................. 71

3.3. Indicadores de algunas condiciones....................................

3.4. Proceso investigativo y descripción de las situaciones problémicas .73

3.5. Dimensiones . .75

3.6. ¿Cómo abordar las técnicas para casos particulares? 77

\section{CAPÍTULO IV}

\section{EL ROL DEL DOCENTE COMO MEDIADOR}

DEL APRENDIZAJE

4.1. Lo ético y lo estético en el acto pedagógico. .84

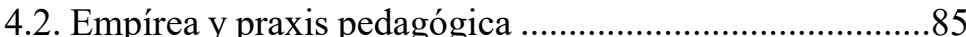

4.3. Desarrollo de competencias educativas..............................87

4.3.1. Las competencias básicas.............................................87

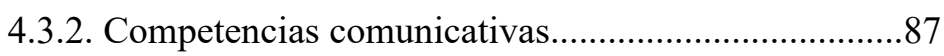

4.3.3. Competencia de autogestión de proyecto de vida......87

4.3.4. Competencias referidas a las nuevas tecnologías de la información y la comunicación........................................8

4.3.5. Competencia de afrontamiento...................................... 88

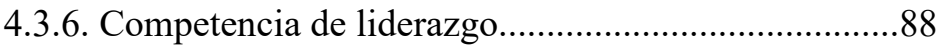

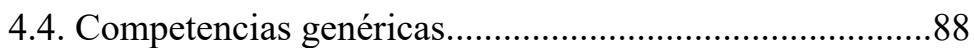

4.4.1.Emprendimiento, gestión de recursos trabajo en equipo y resolución de problemas

4.4.2. Las competencias específicas.......................................89

4.4.3. Calidad educativa...

\section{CAPÍTULO IV}

CONSTRUYENDO EL APRENDIZAJE A TRAVES DEL CONOCIMIENTO DE TECNICAS APROPIADAS

5.1. Técnicas para el trabajo en grupo....................................102

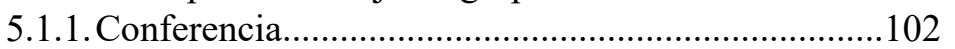

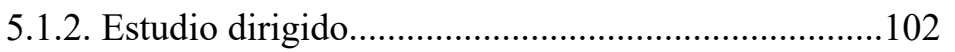


5.1.3.Discusión en grupos

5.1.4. Simposio .104

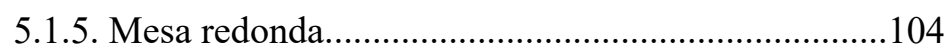

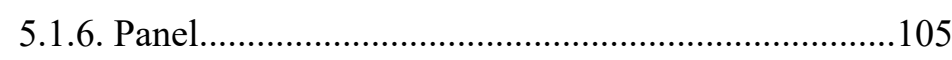

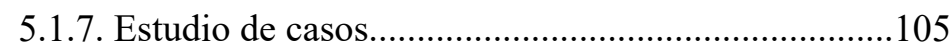

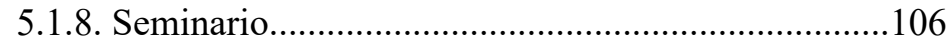

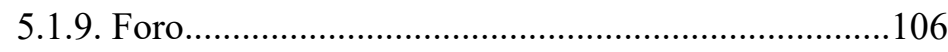

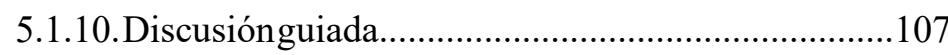

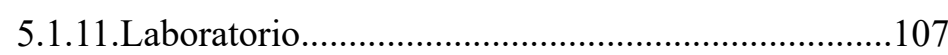

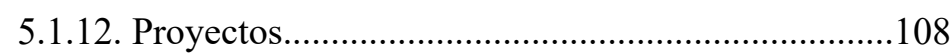

5.1.13. Técnica Phillips 66....................................................109

5.1.14. Técnica de del cesto................................................109

5.1.15. Debate.................................................................. 110

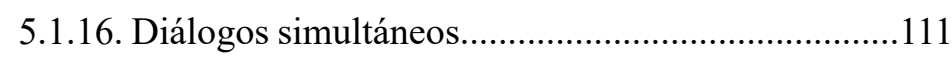

5.1.17. Entrevista..................................................................

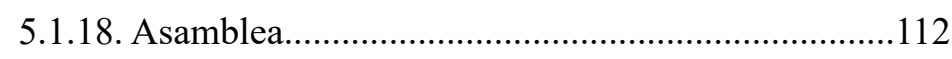

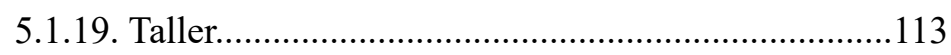

5.1.20. Dinámica de Grupo....................................................113

5.2. Partiendo de los pilares educativos...................................114

5.3. Organización de técnicas pedagógicas para

desarrollar destrezas educativas

5.4. Hacia la construcción de un modelo

instruccional que permita la aprehensión de destrezas.........119

CONCLUSIONES.

BIBLIOGRAFÍA.

\section{PRÓLOGO}

En el entorno educativo, existe un número significativo de estrategias tanto didácticas como metodológicas que significan un sustento esencial para que el docente ejecute su praxis pedagógica como recurso básico de apoyo, el cual constituye una alternativa en su labor para desarrollar los contenidos programáticos y alcanzar los propósitos que se plantearon en la planificación.

Tales herramientas, se componen de una serie de técnicas que al ser tratadas eficientemente en su adecuación, pueden garantizar el aprendizaje eficaz para dar paso a las nuevas perspectivas del conocimiento, cuyo proceso va en correspondencia con el currículo, la planificación y las estrategias que el docente decide implementar en clase.

En ese devenir, el docente juega con sus destrezas y estilos de aprendizaje, al alternar de manera creativa e innovadora las distintas teorías de aprendizaje que conoce, para ofrecer al educando una redimensión de sus estrategias con un enfoque adecuado y consciente de las técnicas, lo que le posibilitará a los estudiantes aprehender el objeto de estudio contundentemente.

Con base a la afirmación anterior, se puede afirmar que la puesta en práctica de técnicas que se amolden a las necesidades del ambiente socio cultural en el que se desenvuelve la relación escuela-maestro-estudiante propicia un ambiente educativo que se conecta con las realidades del entorno y coadyuva al encuentro natural del acto cognoscente.

Por tanto, se considera un avance significativo en los 
estudios pedagógicos que disciernen sobre este tópico temático tan importante, porque engrana la articulación de aspectos cualitativos al ser desarrolladas técnicas especializadas que los docentes han pensado para los aprendices al enfrentar tan loable reto educativo con innovación y creatividad.

De tal manera, que se evidencia en el presente trabajo, aspectos que son considerados como novedosos, al concatenar estructuralmente las técnicas de aprendizaje y las destrezas para su aplicación en la práctica profesional del docente comprometido con una enseñanza que puntualiza la concreción interactiva y eficiente de las estrategias con técnicas que contribuyan al logro delas metas institucionales, educativas, profesionales e incluso personales

\section{Lcda.Esp. MSc. Raquel Lamus}

Investigadora

\section{PREÁMBULO}

Las tendencias educativas actuales se disponen a ser novedosas y vanguardistas, donde el individuo pueda percibir la apropiación del conocimiento con la mínima presión, sino que por el contrario, se sienta en libertad de poder obtenerlo con el uso consensuado entre el docente y el estudiante sobre de estrategias acordes.

Sin embargo, no todas las técnicas que se utilizan dentro de las estrategias bien sean didácticas o metodológicas en un salón de clases, se relacionan con ellas, de manera que se tiende a desequilibrar los métodos y por ende se pierde la armonía que debe existir para que el acto pedagógico se dé eficientemente, lo que repercute en el rendimiento académico de los estudiantes.

Esta visión, permite al docente buscar alternativas de acercamiento óptimo a la implementación de habilidades y destrezas que incidan positivamente en la aplicación de estrategias, por cuanto configura una parte importante en el desarrollo cognitivo de los estudiantes, para explorar cualidades y motivar a los estudiantes mientras aprenden.

Es por ello, que emerge la propuesta de estudio; el cual persigue el interés de develar las técnicas pedagógicas adecuadas para el aprendizaje y la implementación de destrezas a fin de insertar en os ambientes de aprendizaje el esclarecimiento de metodologías que calen con la particularidad de las estrategias que se aplican. 
Desde el punto de vista didáctico y metodológico comprende un desafío académico que sugiere las bases sobre las cuales se debe diseñar la concepción pedagógica con especial atención a los contextos socio históricos, contenidos y potencialidades tanto del docente como del participante; lo cual permite caracterizar la jerarquización del perfil estratégico.

Ahora bien, se han tomado criterios analíticos, cognitivos y metacognitivos, determinados por la planificación y aspectos ontológicos, epistemológicos y axiológicos que posibilitan la operatividad normativa de la acción social y educativa de este libro, por cuanto se considera un aporte teórico importante para los docentes.

\section{INTRODUCCIÓN}

Las técnicas modernas de aprendizaje se sumergen en las distintas estrategias didácticas y metodológicas. Su éxito radica en proponer dentro de la planificación de los contenidos programáticos que exige el currículo la que sea más coherente a los propósitos que se hayan propuesto y las destrezas que se desean desarrollar en los estudiantes durante la jornada pedagógica.

Si bien es cierto que actualmente se cuenta con elementos que amplían la aplicación de destrezas mediante las técnicas de aprendizaje, no es menos cierto que no todos los docentes poseen el dominio suficiente para aplicar las técnicas adecuadas para obtener el conocimiento y las habilidades mínimas que posibiliten aprender contundentemente.

Esto comporta, la fragmentación de la pedagogía en sus cimientos epistemológicos, ontológicos, epistemológicos y axiológicos, dado que penetra los principios estructurales del diseño curricular y desvaloriza los procesos didácticos porque se aleja de las nociones elementales que debe comprender una estrategia en todo su sentido para que esta sea la correcta.

De allí, la importancia que tiene la apropiación y habilidades conceptuales procedimentales y actitudinales en los docentes, que tributen al ejercicio profesoral de calidad en aras de contribuir a mejorar el rendimiento académico dentro de los ambientes de aprendizaje y que este se multiplique en los participantes con la implementación de estrategias adecuadas y relacionadas con sus capacidades. 
De una estrategia óptima con técnicas afinadas, posibilitará en los niños las dimensiones propuestas por la Organización de las Naciones Unidas para el Desarrollo de la Educación y la Cultura UNESCO (1997), cuyas bases se fundamentan en atesorar la educación en cuatro pilares como lo son aprender a conocer, aprender a hacer, aprender a convivir y aprender a ser.

Los temas tratados por la UNESCO, describen el panorama en el que se debe articular la elaboración de técnicas; no obstante, se observa la desactualización de las técnicas pedagógicas, las cuales son elaboradas de forma obsoleta y tradicional, por tanto, es menester que las mismas sean propicias y acorde al tipo de destreza que se desee desarrollar en la enseñanza para dar un impacto positivo tanto en los docentes como en los estudiantes.

Con esta perspectiva, se persigue según Brito (2008:30), "incentivar aprendizajes creativos, transformadores e innovadores, que son clave en una formación integral ante las demandas profesionales que exige la vida contemporánea". A partir de este contexto, surge la pertinencia que de los sistemas educativos aborden esos detalles. Al respecto, es consideración de los autores presentar el presente libro como un aporte a las inquietudes planteadas. 


\section{CAPÍTULO I \\ REFLEXIÓN INICIAL NECESARIA COMO PUNTO DE PARTIDA PARA LA ELABORACION DE TECNICAS PEDAGOGICAS Y EL DESARROLLO DE DESTREZAS}

Como motor de arranque de la investigación, los autores consideran pertinente la identificación de elementos categoriales que componen el presente estudio mediante un proceso de abstracción que sintetice y agrupe la información en unidades de análisis a fin de clasificarlas y profundizar en las mismas. Esta disposición, canaliza la apropiación del estado del arte y permite comprender, manejar y utilizar la terminología adecuada cognoscentemente.

Para ello, se perfilan una serie de situaciones observadas por los autores mediante la observación y praxis educativa, que al sistematizar sus experiencias pudieron confrontar hechos como la utilización de prácticas obsoletas por parte de algunos docentes como una de las limitaciones para que los estudiantes inmersos en el proceso pedagógico logren alcanzar los objetivos de aprendizaje y que a todas luces configura una acción deficiente en detrimento del rendimiento académico.

Otra de las preocupaciones es la rigidez con que se imparten los contenidos académicos, al resistirse a combinar estrategias innovadoras que permitan al docente una nueva visión didáctica en favor de los alumnos que lo reciben. Estas actitudes demuestran inseguridad e inflexibilidad y falta de compromiso vocacional en detrimento del aprendizaje del niño. 
Tales conductas, inciden negativamente en el desarrollo cognitivo estudiantil y se muestran como una brecha que agrieta la armonía del ambiente de aprendizaje, cuya connotación vislumbra las necesidades que deben ser abordadas en el entorno escolar, enmarcado en la realidad de estos hallazgos, al evidenciar la carencia de elementos que optimizan la instrucción educativa.

Las situaciones descritas, no son compatibles con las exigencias educativas que apuntan hacia la transmisión masiva y eficaz de conocimientos teóricos y técnicos evolutivos, adaptados a la civilización cognoscitiva, porque son las bases de las competencias del futuro. Delors (1997:99), en una avanzada progresista y de vanguardia que amplíe la producción y recreación de saberes.

La cita anterior, deja entrever que el comportamiento señalado se aleja del deber ser por lo que contradice la diversificación de recursos didácticos y metódicos que existen o se pueden crear para ser utilizados de manera transversal y disciplinaria en el desarrollo de la jornada pedagógica, en función de los objetivos de aprendizaje trazados.

Por otra parte, algunos docentes son poseedores de amplios conocimientos sobre métodos y estrategias que ponen en práctica en sus aulas, cuyo razonamiento crítico contribuye a fortalecer en sí mismos y en sus participantes la renovación de su ejercicio como valor agregado y preeminente de su quehacer educativo. Es decir, no todos ocupan estas actitudes al desarrollar y promover aptitudes cognitivas de forma consiente, comprometida, responsable y humanista al activar mecanismos de acción contundente en la aprehensión del conocimiento.

Desde este contexto, se asume como reto investigativo indagar sobre las técnicas pedagógicas del aprendizaje y aplicación de destrezas tanto en los maestros como en los niños, como aporte practico a los docentes y estudiantes de educación que tengan inquietudes con respecto a este tópico temático emanada de la experiencia directa.

\section{Algunas aproximaciones teóricas sobre las categorías en estudio}

En este apartado, se contempla un acercamiento a las teorías que sustentan la presente investigación, lo que le imprime un carácter metodológico y sistemático profundo y detallado, sustentado por el estado del arte al documentar el cuerpo epistémico que exhibe la categorización sobre el aprendizaje, las técnicas y las destrezas.

\subsection{Técnicas}

La palabra técnica según El diccionario de la Real Academia Española disponible en línea, proviene del latin technicus, y este del griego. $\tau \varepsilon \chi v \imath \kappa o ́ \varsigma ~ t e c h n i k o ́ s, \tau \varepsilon ́ \chi v \eta \eta$ téchnē 'arte'. Es considerado también un adjetivo perteneciente o relativo a las aplicaciones de las ciencias y las artes, de lo cual se infiere que es una combinación de estos dos elementos.

De acuerdo a la Dirección de Investigación y Desarrollo Educativo de la Vicerrectoría Académica del Instituto Tecnológico y de Estudios Superiores de Monterrey compilado 
por Garza, (2000:5), son procedimientos que a través de una secuencia determinan de ordenadamente la forma de llevar a cabo un proceso al definir claramente cómo ha de ser guiado el curso de las acciones para conseguir los objetivos educacionales propuestos.

Partiendo de este concepto, se considera que la técnica es un componente esencial en los procedimientos metodológicos y forma parte de las estrategias didácticas dado que conforman un compendio de herramientas útiles y necesarias en las que el docente encuentra el apoyo para administrar la planificación de sus clases y dirigir a los estudiantes.

En educación, la Técnica contribuye a la organización lógica del aprendizaje al precisar de manera detallada las especificaciones metodológicas que son utilizadas como instrumentos psicopedagógicos coherentes con la exploración de aptitudes para ser posteriormente evaluadas por los profesores en la promoción y ejecución de sus experiencias académicas.

Al ubicarse con las técnicas adecuadas, tanto los maestros como los estudiantes tienen a su favor una estructura tendiente a facilitar y simplificar el aprendizaje de forma propositiva y creativa sin alejarse de lo concerniente al academicismo. Esto, no solo provee el dominio del tema a estudiar y la aprehensión de competencias, sino también de motivación a ambos actores en beneficio del alcance de los objetivos y metas, además de darle un matiz personal y profesional.
Imagen 1. La técnica como componente de la estrategia

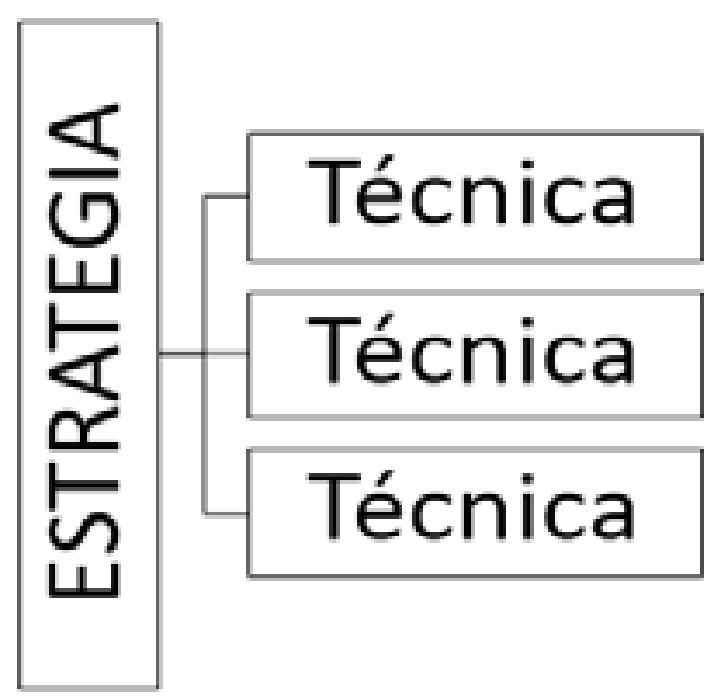

Fuente: Revisión bibliográfica consultada. Elaboración propia (2019).

\subsection{Pedagogía}

Etimológicamente, según el diccionario etimológico disponible en la web, la derivación de esta palabra proviene del griego paidos cuyo significado es niño y agein que se expresa como guiar, conducir. Por tanto, en un sentido concreto, la pedagogía es una habilidad magistral para instruir y formar a los sujetos desde su primera infancia en la conducción del conocimiento.

A este respecto, Fullat (1992), define la pedagogía como un 
conjunto de saberes que se ocupan de la educación, tendiente a fortalecer los aspectos psicológicos del niño en la sociedad, por eso la precisa como ciencia de carácter psicosocial que aborda aspectos integrales físicos y emocionales del educando e incluso dentro y fuera del ambiente de aprendizaje.

Por su parte, Kant (2009: 45-50), señala que la pedagogía o doctrina de la educación es física o práctica, por cuanto se disponen dos condiciones donde se combinan en un solo sistema contextos mecánicos, teóricos y experimentales. También afirma que el pedagogo es un guía que enseña para la vida (Op. cit:45), dado que no se limita solamente a lo académico. De allí la conexión servicial y vocacional que el docente debe ofrecer.

\subsection{Técnicas pedagógicas}

Al hacer énfasis en el análisis de los conceptos de técnicas $\mathrm{y}$ pedagogía se infiere que de la yuxtaposición de ambas definiciones emergen los significados que le dan sentido a la presente investigación, en el entendido de que son las técnicas pedagógicas las que se indagan en este contexto indagatorio y permiten abordar de una manera más pragmática y operativa los entornos pedagógicos.

En ese orden de ideas, apunta Navarro (2011), que las técnicas pedagógicas son una parte fundamental en el proceso educativo que comprende la enseñanza y el aprendizaje, dado que las mismas se encuentran inmersas dentro de las actividades que el docente ha planificado para posteriormente ejecutar a objeto de facilitar en los estudiantes la construcción del conocimiento.

Esta definición, revela la importancia de implementar

$$
28
$$

técnicas pedagógicas apropiadas en concordancia con los contenidos educativos y los objetivos de aprendizaje trazados, para que se evite la improvisación y poca preparación de la clase, sino que por el contrario se estructure de forma bien organizada la impartición de estos.

Asimismo, Nassif, (1977), determina que las técnicas pedagógicas son un "Conjunto de procedimientos de que se vale la ciencia o el arte para lograr un determinado resultado. En general un recurso que el hombre utiliza como medio para alcanzar un objetivo". Es también relevante destacar que en este concepto el autor ofrece una visión en la que se puede interpretar como un medio para lograr instrumentalizar las estrategias didácticas y metodológicas de la planificación.

\subsection{Aprendizaje}

Este término permite construir la plataforma epistémica relacionada con el presente estudio. En opinión de Pérez y Sacristán (1992), “el aprendizaje es la motivación intrínseca que cada individuo tiene por instruirse, y conocer algo más para poder afirmar el conocimiento que posee". A juicio de este autor aprender es una decisión personal que permite mantener o expandir la comprensión de los objetos cognoscibles.

Una concepción parecida la tienen Sobrado, Cauce y Rial (2002:58), quienes expresan que el aprendizaje es un proceso verificable que tiene lugar dentro de la persona en el que se activa la presencia de pensamiento lógico y racional, así como los sentimientos, las emociones, la intuición, la deducción y la acción, pues se armonizan en un compendio contextual en el acto 
educativo y en la vida en general para adquirir conocimiento.

Se destaca igualmente la concepción de Vásquez (2010:1415), quien expresa que el aprendizaje es un" proceso activo, participativo, organizado y de socialización que favorece la apropiación de conocimientos, habilidades, destrezas". La idea expuesta, encierra un compendio de elementos que dinamizan la interacción de operaciones mentales, cognitivas y metacognitivas.

Ahora bien, para dar efectividad al aprendizaje es menester que el educador transfiera los conocimientos con base a las distintas teorías existentes y adecuen su práctica enmarcadas en la representación de los modelos de aprendizaje que crea pertinente como marco de referencia epistemológica que permita descubrir y describir el conocimiento adquirido.

\subsection{Algunos modelos o teorías sobre el aprendizaje}

Una teoría de aprendizaje es, en palabras de Joyce y Weil (1985:11) "un plan estructurado que puede usarse para configurar un curriculum, para diseñar materiales de enseñanza y para orientar la enseñanza en las aulas". Los autores hacen referencia a la organización del aprendizaje constituido por un orden específico subyacente del contenido académico, que deriva de la existencia y apropiación de las teorías modélicas que soportan el aprendizaje y que se describen en el punto subsiguiente.

\subsubsection{Teoría Conductista}

La teoría conductista fue creada tras los experimentos de John B. Watson (1878-1958), basada en la capacidad del individuo para condicionar o controlar el hecho de producir una respuesta. En el aprendizaje, esta teoría se enfoca en los comportamientos y la frecuencia con que se manifiestan los cambios, al suponer que ocurre una transformación positiva en el estudiante al recibir una información (estimulo). Fonseca \& Bencomo (2011:81).

Es decir, el docente en su labor durante la jornada, debe observar detenidamente al estudiante para poder determinar si con las estrategias aplicadas durante la conducción pedagógica, se pudo lograr la transferencia contundente de conocimientos en el niño, de manera que estos puedan desarrollar su potencial en forma permanente.

Imagen 2. Teoría Conductista

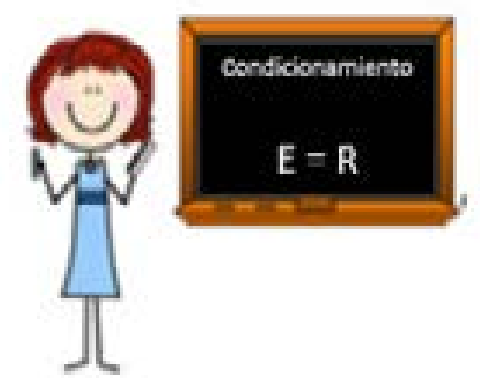

Fuente: Elaboración propia a partir del Kit familia palito (2019). 


\subsubsection{Teoría cognitivista}

Para Fonseca \& Bencomo (2001:81-82), la teoría cognitivista es un "fenómeno mental, central, que se produce mediante la comprensión, la reflexión, el pensamiento y el discernimiento. Es decir el razonamiento". Esta teoría considera según los autores de la cita, un proceso lógico que da lugar a la un proceso de abstracción, introspección y extracción donde el sujeto aprehende el conocimiento tomándolo para sí.

En esta secuencia reflexiva, la teoría cognitivista se manifiesta en los estudiantes desarrollando un pensamiento crítico, donde la codificación de la información regula, modifica, adapta y transforma los juicios que tenían y el nous se exterioriza con la ampliación de su intelecto, adquiriendo sabiduría en un vínculo epistemológico.

Imagen 3. Teoría cognitivista

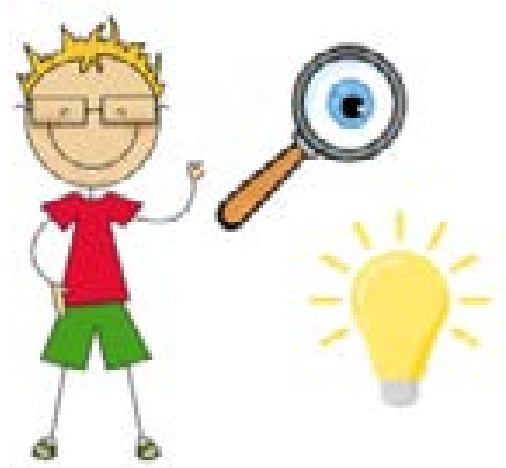

Fuente: Elaboración propia a partir del Kit familia palito (2019).

\subsubsection{Teoría constructivista:}

La teoría constructivista persigue de acuerdo a Fonseca \& Bencomo (2001:93), que el participante construya la realidad histórica, cultural, social y científica tal y como la ve, la siente y la vive en concordancia a su estructura mental y la exprese ante su entorno, de manera que pueda observarla como un escenario que presenta los hechos lo más objetivo posible.

La característica principal deriva, del hecho de que los sujetos edifican los cimientos de su conocimiento participando en su propio levantamiento arquitectónico por así decirlo, dado que los mismos son los agentes activos que dinamizan el aprendizaje de acuerdo a las condiciones psicológicas, cognitivas, físicas, afectivas y sociales.

\section{Imagen 4. Teoría Constructivista}

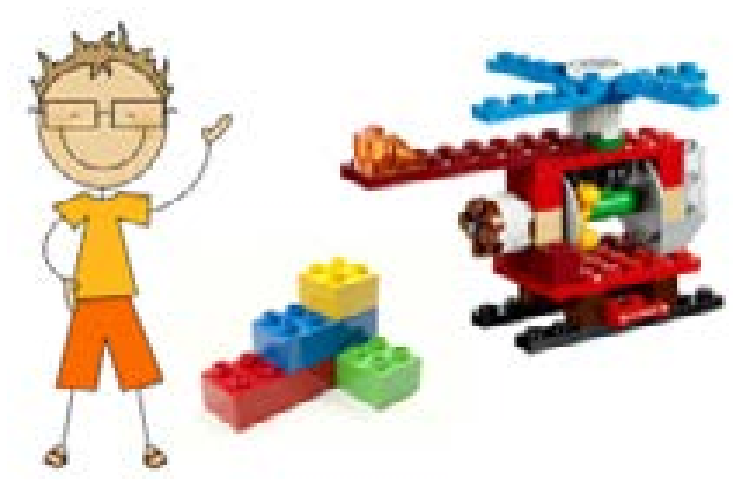

Fuente: Elaboración propia a partir del Kit familia palito (2019). 


\subsubsection{Teoría humanista}

El humanismo, se centra en las experiencias exclusivamente humanas, sopesadas por las condiciones psicológicas e intelectuales donde cada individuo tiene su particularidad y el desarrollo de sus potencialidades se basan en el respeto, la empatía y la solidaridad. Fue esencialmente una revolución pedagógica, cuya característica principal es formar a un ser integro e integral. Abbagnano, \& Visalberghi (1992:142).

En atención a humanismo, Morin (2000:65), desde su estudio sobre la complejidad de la condición humana como una de las aristas primarias de la educación, asienta que la toma de conocimientos es similar a la toma de conciencia desde diversidad de los individuos, de los pueblos, de las culturas, sobre nuestro arraigamiento como ciudadanos de la Tierra. Es decir, un individuo capaz de ver, entender y aceptar al otro tal y como es, sin tratar de cambiarlo.

\section{Imagen 5. Teoría humanista}

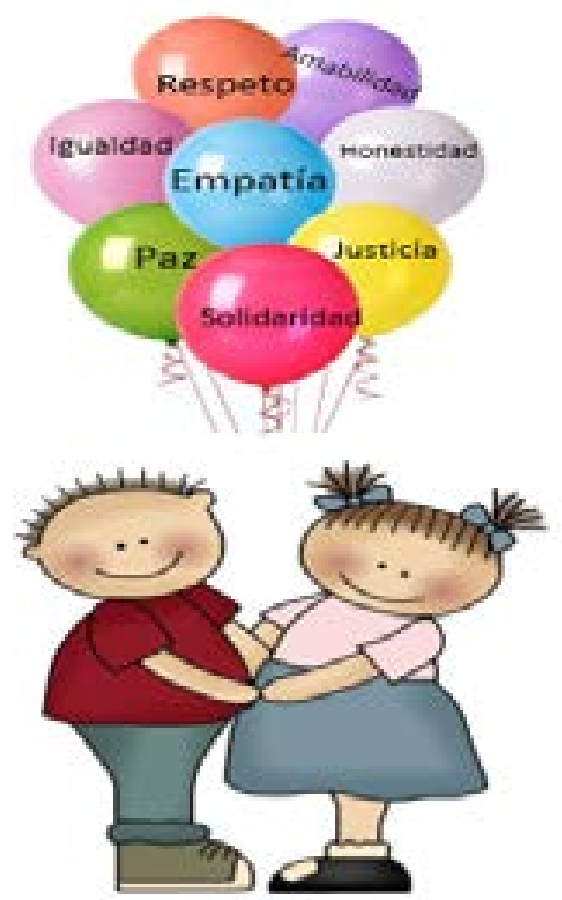

Fuente: Elaboración propia a partir del Kit familia palito (2019).

\subsubsection{Teoría de la asimilación y acomodación:}

A este modelo también se le cataloga como la teoría genética y "Consiste en la incorporación de los objetos dentro de los esquemas de comportamiento, que no son otra cosa sino el armazón de acciones que el hombre puede reproducir activamente en la realidad". Piaget (1948). Partiendo de estos 
supuestos, los sujetos pueden representar en sus acciones todo lo aprendido según su proceso cognitivo, madurez intelectual, desarrollo biológico, interacción social y experiencias, por ello Piaget (1970), lo denomina como la "Integración de elementos exteriores", mientras estos se relacionan y se adaptan los nuevos conocimientos.

Piaget, describe el desarrollo en tres grandes periodos en correspondencia con tres tipos de inteligencia o estructuras cognitivas, denominadas preoperacional, operaciones concretas $\mathrm{y}$ operaciones formales y concluye que el aprendizaje del estudiante debe estar interconectado con su estadio mental:

a) Periodo sensorio-motriz: Es la etapa inicial que comienza con el nacimiento hasta los dos años, donde el lactante logra identificar su medioambiente y comprende que es parte de él, atendiendo a los hechos repetitivos para introducirlos en su estructura mental.

Imagen 6. Periodo sensorio-motriz.

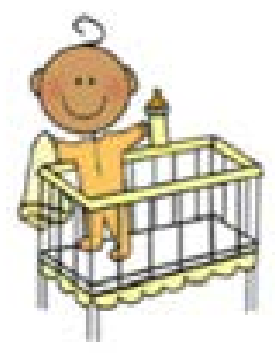

Fuente: Elaboración propia a partir del Kit familia palito (2019). b) Periodo de las operaciones concretas: En este curso que se emprende desde los dos años hasta los once, la fase preoperatoria prepara al niño para utilizar los símbolos, las señas y aprender a hablar con el uso de la lengua. En la fase subsiguiente ya comienzan las operaciones concretas y predomina la lógica y el orden.

Imagen 7. Periodo de las operaciones concretas

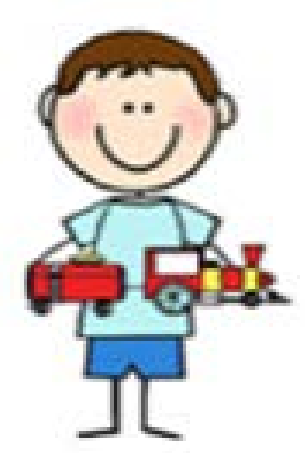

Fuente: Elaboración propia a partir del Kit familia palito (2019).

c) Periodo de las operaciones formales: A partir de los doce años en adelante, ocurre una metamorfosis con la transición hacia el pensamiento abstracto, donde se obtiene capacidad mental para comprobar hipótesis que el mismo se formula. 
Imagen 8. Periodo de las operaciones formales.

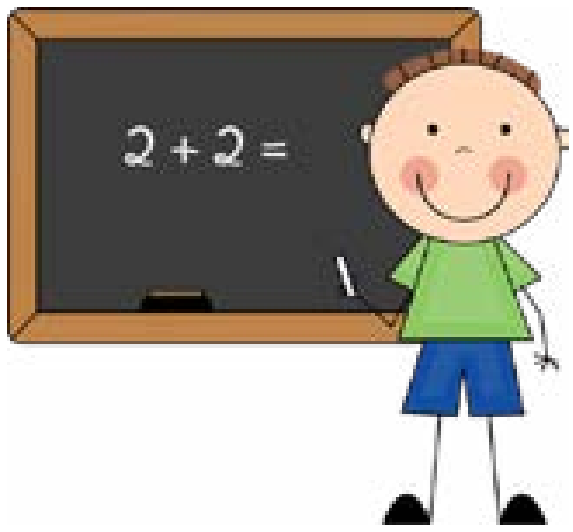

Fuente: Elaboración propia a partir del Kit familia palito (2019).

\subsubsection{Aprendizaje significativo}

Otras de las teorías de aprendizaje es el denominado significativo. Para ilustrarlo, Ausubel (1978) señala que dicho aprendizaje se da cuando pueden relacionarse los objetos cognoscentes de modo no arbitrario con lo que el alumno ya tiene previamente concebido, sabe y conoce y en ese contraste se crean nuevos conocimientos partiendo de lo preconcebido.

Paralelamente, Piaget (1967), sienta el aprendizaje significativo como una interacción resultante de las aproximaciones sucesivas entre el sujeto y el objeto, al recibir información de su entorno, las cuales se van almacenando y al ser relacionadas y clasificadas en su estructura mental, consigue organizar la transformación del conocimiento anticipado que posee.

Imagen 9. Aprendizaje significativo

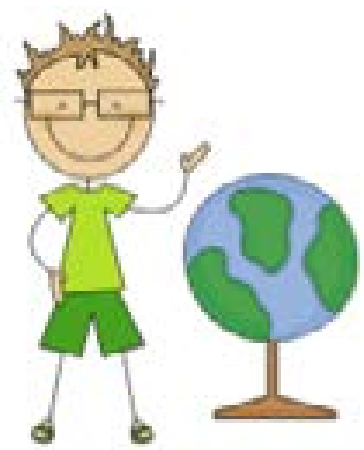

Fuente: Elaboración propia a partir del Kit familia palito

(2019).

\subsubsection{Interpretación socio-histórico-cultural del aprendizaje}

En función del proceso de aprendizaje, el docente debe auxiliarse de manera temporal para la ejecución de una intervención estructurada dependiendo de las necesidades del aprendiz si así lo ameritara; como especie de un acompañamiento pedagógico cuando se considere que ya puede desempeñarse por sí solo y regular su propio desempeño; es decir, autorregularse (Vygotsky, 1993).

Sobre este escenario, la interpretación socio-históricocultural del aprendizaje de Vygotsky acuñada como Zona de Desarrollo Próximo (ZDP), concibe un espacio cognitivo que se 
enfoca en la psicogenética del hombre y que a su vez procede de la ley general del desarrollo de los procesos psíquicos superiores humanos al utilizar instrumentos semánticos que estos dominan. Corral (2001:72).

En fin, de acuerdo a los contenidos curriculares y objetivos, aunado a los rasgos cognitivos, afectivos y fisiológicos del estudiante, el docente podrá determinar la forma de abordar sus técnicas y estrategias con el objetivo de que éstos puedan procesar los conocimientos en respuesta a los estímulos recibidos a través de sus sentidos y así alcanzar aprendizajes eficaces, por ello, es necesario que el docente mediante un proceso de reflexión, conozca todos los tipos y estilos de aprendizaje e incluso aplicar uno o más modelos que permitan al individuo acceder al conocimiento.

Imagen 10. Zona de Desarrollo Próximo

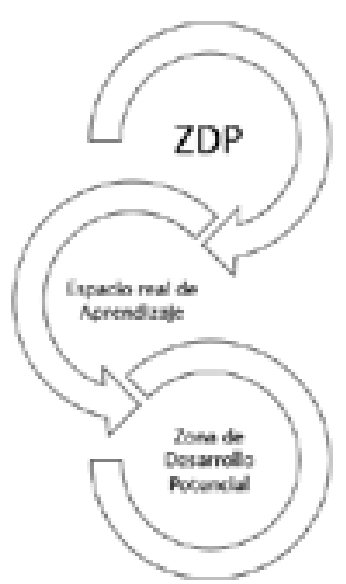

Fuente: Elaboración propia (2019).

\subsection{Destrezas para el aprendizaje pedagógico}

Una destreza es aquella que se define como la "capacidad o facultad que permite a una persona realizar un acto en un tiempo determinado". Ríos (2006:396). En otras palabras, una destreza es la habilidad que se tiene para ejecutar una acción con pericia. Tal virtud le ofrece la posibilidad de realizar actividades de una manera más fluida, fácil, rápido y cómoda.

Sobre la validez de las enunciaciones que anteceden, para gestionar y procesar la información en el acto comunicativo del aprendizaje, el docente debe concentrarse en lo que verdaderamente necesita para acudir a las técnicas convenientes y apropiadas así como las habilidades a desarrollar en sí mismo $\mathrm{y}$ en el estudiante.

En consecuencia, las destrezas proporcionan el plus necesario para poner en acción las habilidades del docente porque al dominarlas, le permite analizar las metodologías y estrategias didácticas adecuadas para ordenar, procesar y gestionar la información que desea transmitir durante el acto pedagógico y a su vez potencia su desempeño.

Para lograr tal comedido, las condiciones psicológicas de los docentes y sus conocimientos científico-técnicos deben propender hacia la orientación lógica y organizada de la información para poder en primer momento planificar los contenidos para que en un segundo instante poder transmitir la información a los estudiantes.

En este sentido, de Tünnermann (2008), proyecta ocho capacidades intrínsecas en el docente, que son:

41 
a) Reflexión crítica: Es el abordaje introvertido que permite esclarecer, valorar, analizar y comprender la información.

b) Resolución de problemas: Es el estudio concreto de una situación que fomenta la participación.

c) Adaptación a las nuevas situaciones: Es el ajuste o acomodación a contextos o circunstancia que se presentan a diario, propias del proceso de aprendizaje.

d) Selección de información relevante de los ámbitos del trabajo, la cultura y el ejercicio de la ciudadanía, para tomar decisiones fundamentadas: Es el estudio previo, investigación y la clasificación de los contenidos.

f) Seguir aprendiendo en contextos de cambio tecnológico y sociocultural acelerado y de expansión permanente del conocimiento: Son las competencias que se alcanzan a través del estudio y la preparación.

g) Buscar espacios intermedios de conexión entre los contenidos de las diversas disciplinas: Es trabajar los contenidos programáticos de forma transversal a través de la interdisciplinariedad.

h) Emprender proyectos en cuyo desarrollo se apliquen conocimientos o procedimientos propios de diversas materias: Promover iniciativas de participación en eventos académicos, congresos y foros, entre otros.

i) Disfrutar de la lectura y la escritura, del ejercicio del pensamiento y de la vida intelectual: Se trata de que la praxis educativa sea placentera y el docente pueda recrearse mientras se desarrolla profesionalmente.

\subsection{Los estilos de aprendizaje y su relación con las destrezas}

Derivado de la diversidad y la particularidad de cada sujeto, el individuo no aprende en forma igual dado que sus procesos cognitivos son diferentes por cuanto responden a situaciones peculiares de su vida y desarrollo físico y psicológico. Esta afirmación concuerda con la concepción que sobre estilos de aprendizaje desarrolla el gobierno de Panamá (2005:1), al afirmar: "el término se refiere al hecho de que cuando queremos aprender algo cada uno de nosotros utiliza su propio método o conjunto de estrategias".

Con base a esta definición, los autores infieren que el estilo de aprendizaje es el modo de cultivar el conocimiento, condicionado por los intereses del individuo, así como su madurez y desarrollo biopsicosocial para procesar información que recibe de las diferentes áreas como la lingüística, la lógica matemática, espacial, corporal, musical, naturalista, entre otras.

\subsubsection{El Modelo de los Cuadrantes Cerebrales de Herr-} mann

El modelo de Herrmann (1991:121-127), es un cruce de dos modelos que le anteceden, el cual se encuentra sustentado en los modelos de Sperry (1961), quien investiga sobre los hemisferios izquierdo y derecho; en combinación con el modelo de McLean (1967), que analiza en su estudio el cerebro cortical y límbico. Hermann (op.cit), intenta escudriñar en el origen de la creatividad personal de acuerdo al dominio que cada individuo posee. 
En ese orden de ideas, el docente de acuerdo a sus intereses individuales y profesionales y partiendo de cada situación particular, se ubica en uno de esos cuadrantes que postula el autor. El modelo en si se divide en cuatro cuadrantes. El cuadrante ubicado en la parte superior izquierda se posiciona lo cuantitativo, lógico y analítico, basado en hechos. En la parte inferior del mismo punto se encuentra el pensamiento organizado, secuencial, planeador y detallado. Del lado derecho en su parte posterior se sitúa la tendencia holístico, intuitiva, integradora y sintetizadora. Por su parte en el cuadrante inferior del mismo lado, esta lo interpersonal, basado en los sentimientos, lo estético y lo personal.

Imagen 11. Cuadrantes Cerebrales de Herrmann

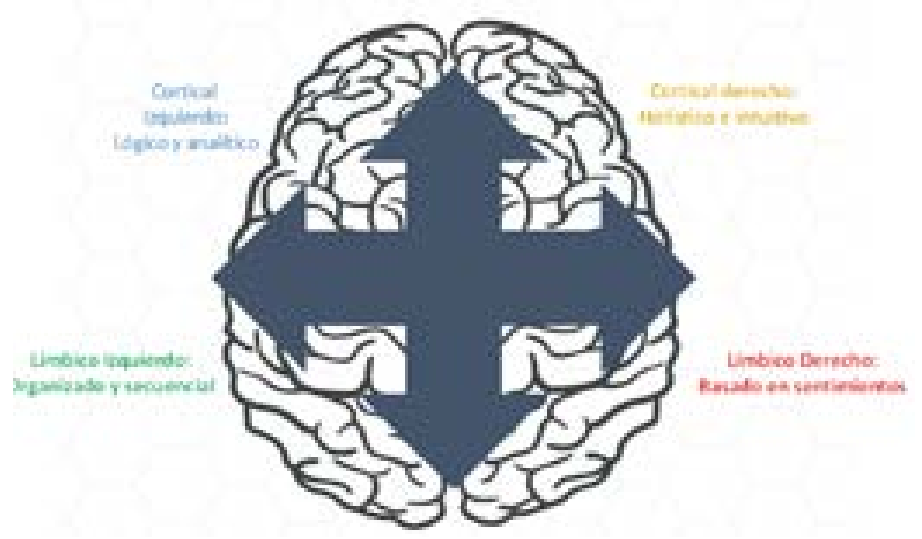

Fuente: Elaboración propia (2019).

\subsubsection{Modelo de Felder y Silverman}

El modelo de Felder y Silverman (1988), se dimensiona en estas cinco aristas:

a) Sensitivos-Intuitivos: Se deriva de la información que se recibe del exterior y del interior de la persona. Del exterior, por medio de sus sentidos y del interior de sus registros memorísticos y recuerdos.

Imagen 12. Dimensión Sensitivo-intuitivo

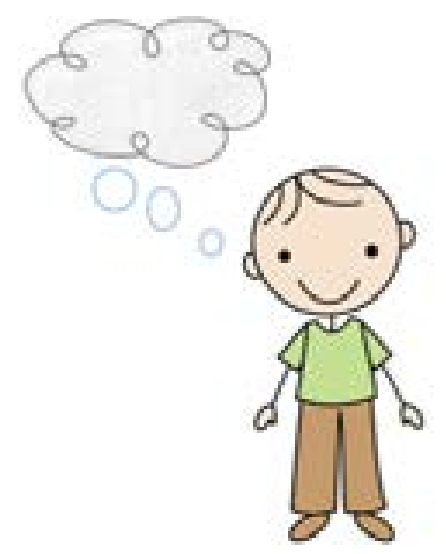

Fuente: Elaboración propia a partir del Kit familia palito (2019).

b) Visuales-verbales: Son las representaciones orales y escritas que ven y escuchan. 
Imagen 13. Dimensiones Visuales-verbales

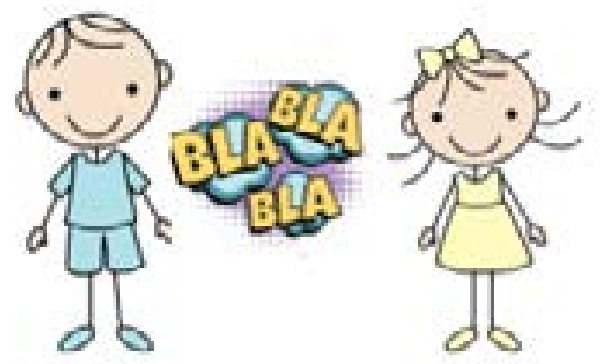

Fuente: Elaboración propia a partir del Kit familia palito (2019).

c) Inductivos-Deductivos: Son los estímulos recibidos que conllevan a teorizar conclusiones.

Imagen 14. Dimensión Inductivo-deductivo

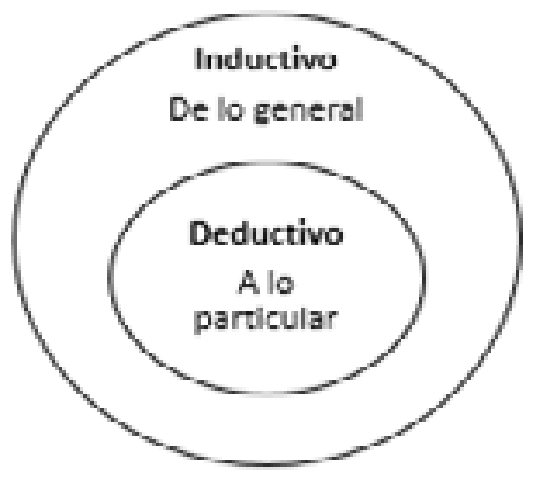

Fuente: Elaboración propia (2019). d) Secuenciales-Globales: Es la secuencia lógica que integra la información y la transforma en conocimiento.

Imagen 15. Dimensión secuencial-global

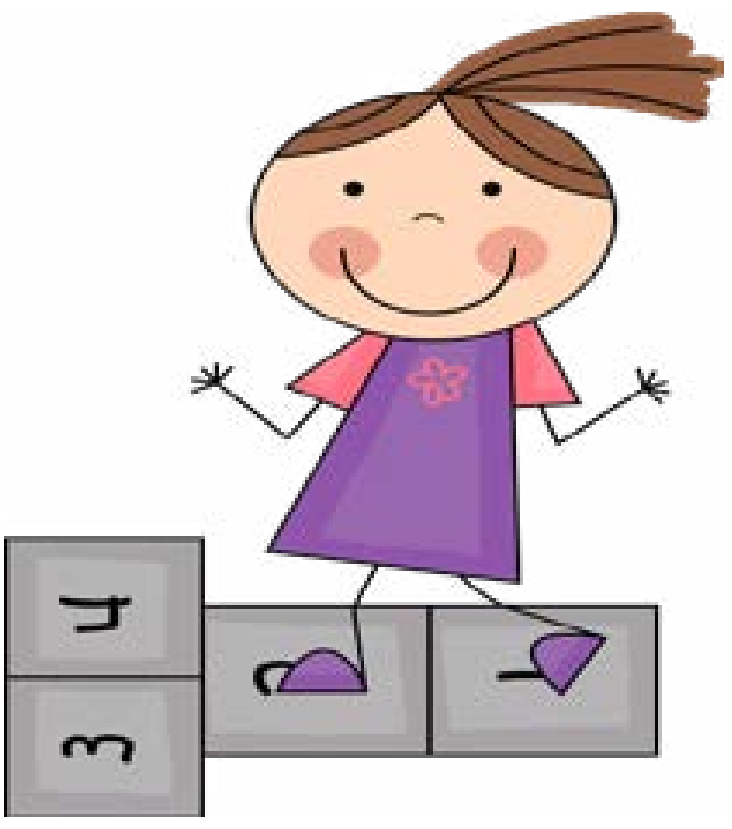

Fuente: Elaboración propia a partir del Kit familia palito (2019).

e) Activos y Reflexivos: El proceso introspectivo que se realiza combinado con las actividades físicas. 


\section{Imagen 16. Dimensión Activa y Reflexiva}

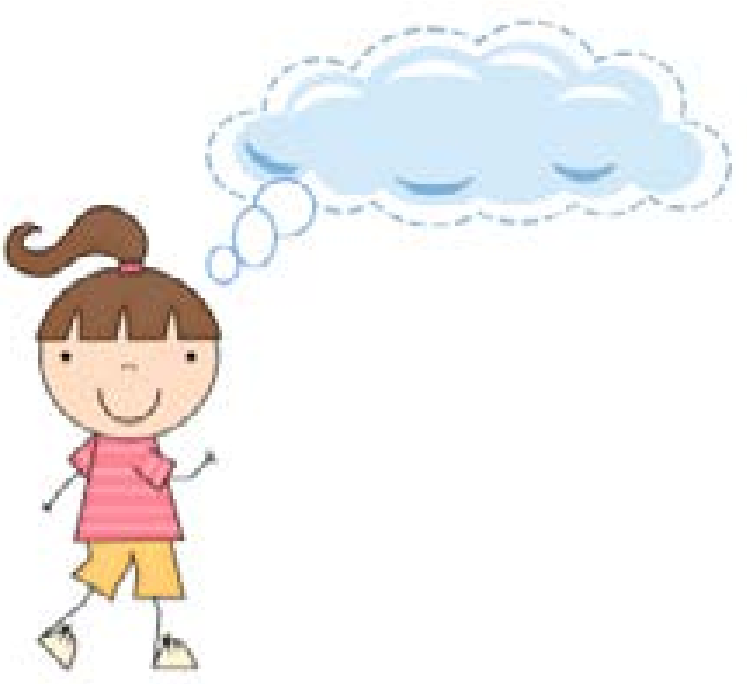

Fuente: Elaboración propia a partir del Kit familia palito (2019).

\subsubsection{Modelo de Kolb:}

El modelo de Kolb (1990), postula dos formas de aprender. La primera, parte de la empírea bien sea concreta o abstracta; y la segunda experimentando y reflexionando sobre estas dos acciones para contrastarlas y procesarlas. Estas dos perspectivas contribuyen a encauzar la información y transformarla en conocimiento.
Imagen 17. Modelo de Kolb

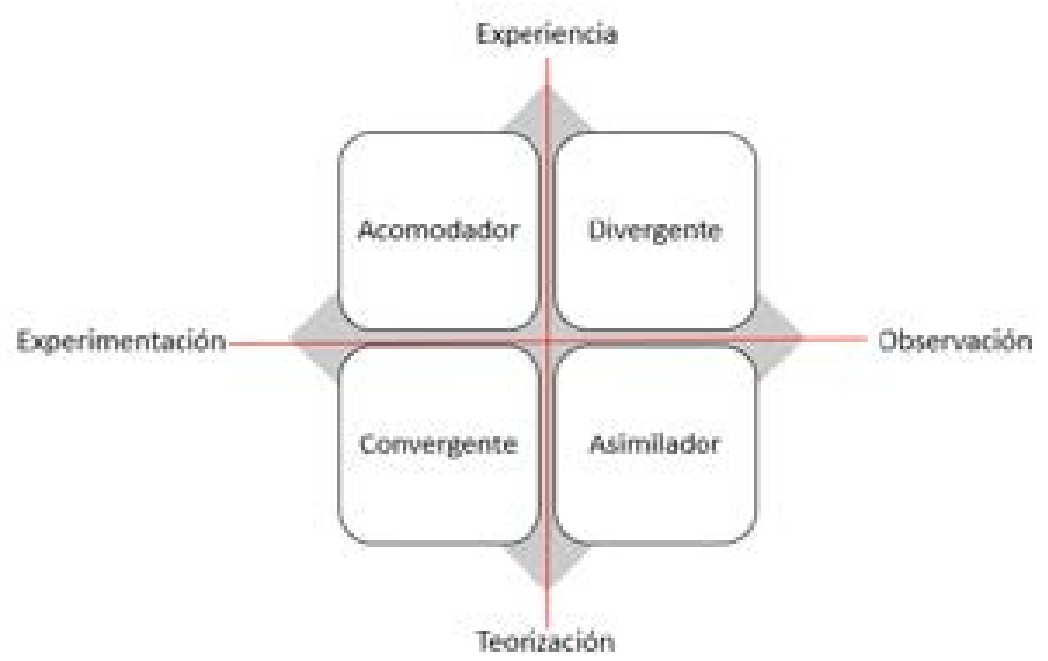

Fuente: Elaboración propia (2019)

\subsubsection{Modelo de la Programación Neurolingüística de Bandler y Grinder:}

La Programación Neurolingüística (PNL), en palabras de Grinder y Bandler (1975), es la ciencia de las oportunidades, al ofrecer una serie de alternativas diferentes con base al funcionamiento del cerebro. Se trata de un modelo donde se puede orientar la información desde las representaciones que perciben lo visual, lo auditivo y lo kinestésico.

El sistema visual hace que las personas ejerciten la memoria con imágenes como diagramas y figuras. En lo que corresponde a lo auditivo, estimulan el conocimiento escuchando sonidos e 
interactuando de forma oral; por su parte, los kinestésicos son sensoriales y reciben la información a través de las emociones y sentimientos.

\section{Imagen 18. Modelo de PNL}

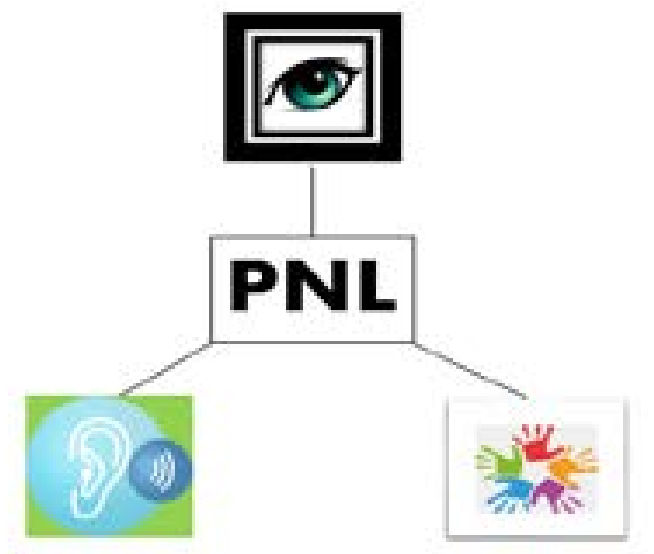

Fuente: Elaboración propia (2019

\subsection{Técnicas de aprendizaje como paradigma educativo en el desarrollo de destrezas}

En el recorrido histórico del mundo, el hombre en su lucha constante por conquistar el conocimiento se adscribe a paradigmas que se establecen en relación al estilo de pensamiento adquirido y sigue patrones que al pasar el tiempo se quedan arraigados en su cultura y forma de vida sin dejar cabida a nuevos esquemas.

Las diferentes formas de producir conocimiento demandan la adecuación de procesos innovadores que logren insertarse socialmente en la transformación y evolución de la contemporaneidad donde prevalecen los entornos web. En esa coyuntura, se atienden la acentuación del sujeto en la acción para incidir en la necesidad de aprender del estudiante y desplaza la casi exclusiva anterior de enseñar, del profesorado; para adquirir un rol de acompañante, de guía, tutor, de impulsor de aprendizajes. Romea (2001:108).

En este orden de ideas, surgen nuevos retos para la apropiación del conocimiento y es tarea del docente como mediador del aprendizaje darse a la tarea de aprehender formas pedagogas innovadoras no rígidas, flexibles y adaptables al entorno sociocultural del individuo

Es decir, poder aplicar en una misma estrategia didáctica distintas técnicas de aprendizaje que se acomoden a la necesidad educativa del estudiante y a las potencialidades académicas y creativas de los docentes y a los temas que se pretenden desarrollar con intención epistemológica, axiológica, sociológica, teleológica, ontológica y metodológica que sirva como herramienta analítica y conceptual del objeto de estudio. 


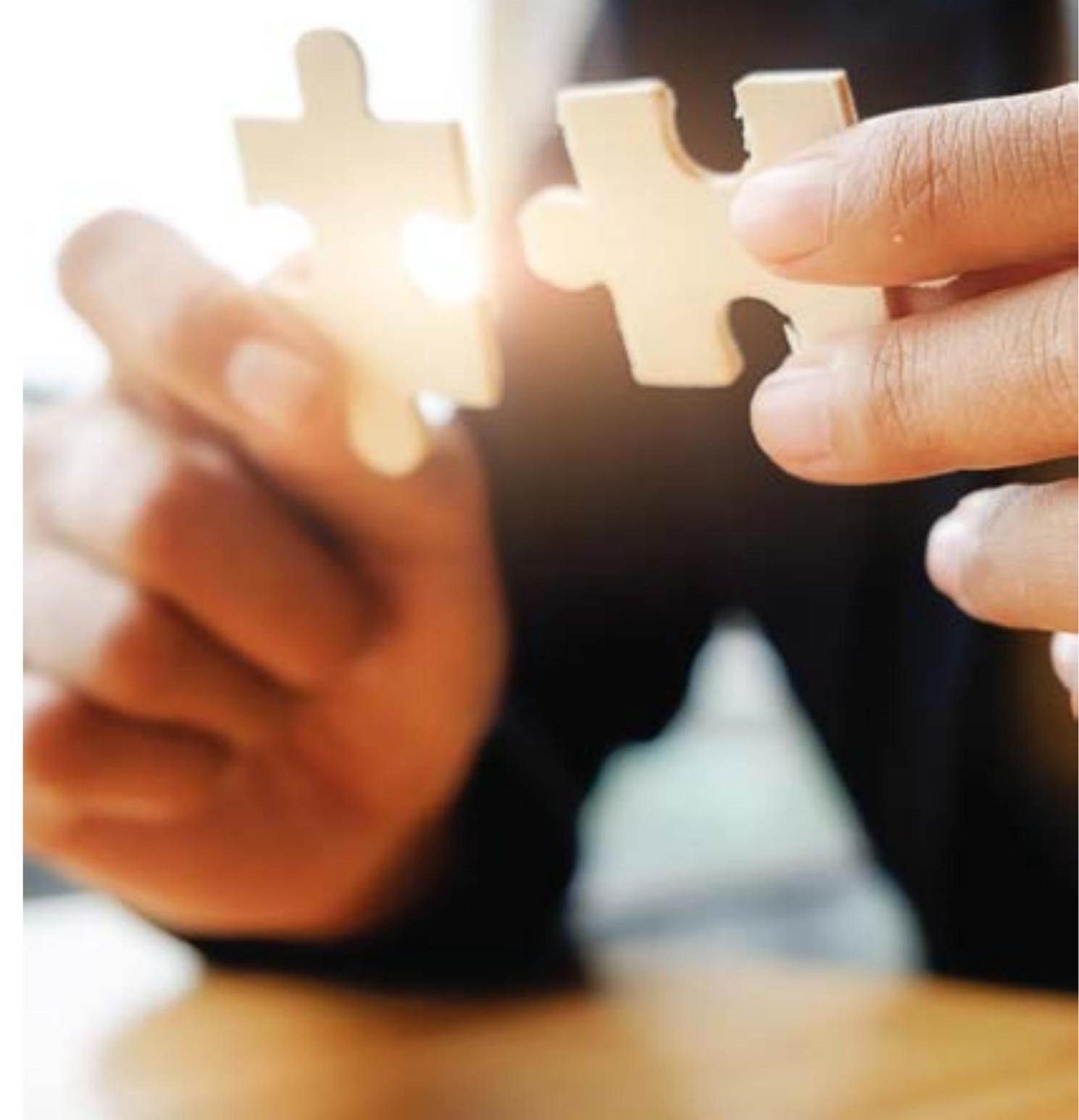




\section{CAPÍTULO II}

\section{LAS TECNICAS DE APRENDIZAJE EN LA PLANIFICACIÓN PEDAGÓGICA}

Si bien es cierto que Tyler (1949) con su modelo conductista buscaba enmarcar los objetivos dentro de una estructura algo rígida, no es menos cierto que su propuesta ha proporcionado un elemento útil para los docentes al ordenar de manera sistemática los elementos que dinamizan el acto pedagógico. Se trata de plasmar en un papel de trabajo las formas, estrategias y técnicas con las que se abordan los contenidos programáticos.

Al respecto, Guerrero y Borjas (2006:57), describen a la planificación como una función básica con carácter operativo, partiendo de los supuestos que arroja el diagnóstico inicial, las políticas educativas, los programas y ejes temáticos así como los objetivos que se deseen alcanzar, los cuales se ejecutan durante el periodo escolar en un contexto situacional específico.

La planificación educativa debe favorecer al estudiante y tener coherencia con el proyecto educativo institucional. Es, un plan de acción concreto que contribuye a organizar la labor educativa como docentes, articulando el conjunto de contenidos, opciones metodológicas, estrategias educativas, textos y materiales para secuenciar las actividades que han de realizar en su quehacer diario dentro del aula, con la finalidad de mejorar u optimizar el proceso de aprendizaje y, por ende, la calidad educativa que se enmarca en el calendario escolar.

El plan además de ser consistente, debe ser flexible, sencillo y que brinde la posibilidad de una secuencia lógica para dar 
continuidad a los objetivos que hagan posible la gestión académica y viabilice el aprendizaje con aspectos teóricos conceptuales operativos y prácticos que rigen los saberes, cuyos objetivos se orienten hacia el desarrollo del conocimiento.

\subsection{Etapas Organizativas para la planificación}

La organización del aprendizaje no puede improvisarse. Así lo especifican las orientaciones para la planificación de la enseñanza del gobierno de Chile (2009), al plantear que el sistema organizativo de una planificación de la jornada, contempla 3 momentos denominados Inicio, desarrollo y Cierre, por los que se pasea el docente y que deben contemplarse a la hora de planificar.

a) Inicio: es el primer instante de contacto entre el docente y los educandos, donde se realiza el saludo, se aplica alguna estrategia motivacional referente al tema que se va a tratar, se hace la presentación del tema a desarrollar y las normas para trabajar

b) Desarrollo: en el recorrido de este intervalo, el docente avanza hacia la transferencia de conocimientos aplicando las estrategias ya contempladas en su planificación mediante una serie de actividades y estrategias y se da el intercambio de saberes mediante la problematización, los planteamientos y la interacción con los participantes.

c) Cierre: al finalizar la clase el docente debe clausurar el encuentro haciendo un resumen sistematizado de lo aprendido a través de un análisis profundo. También, puede finalizar con alguna dinámica, juego o actividad especial que le posibilite valorar la aprehensión del conocimiento en los estudiantes.

La pregunta de análisis que debe plantearse todo docente que comienza a planificar es la siguiente: ¿Qué técnicas son las adecuadas para utilizar dentro de las estrategias didácticas y metodológicas en el tratamiento de las etapas organizativas de la planificación y ejecución de la jornada pedagógica?

La respuesta a la interrogante anterior, se encuentra en el proceso de preparación de las clases, cuando se toman las decisiones sobre el material de apoyo que permitan ajustar las tácticas acordes a las estrategias para desarrollar eficaz y eficientemente el aprendizaje contribuyendo a ejecutar la estrategia por ser la más idónea.

Imagen 19. Etapas Organizativas para la planificación

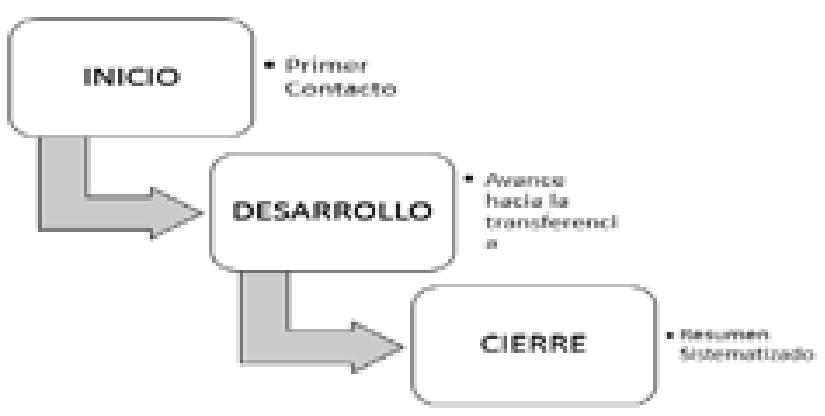

Fuente: Elaboración propia 


\subsection{Principios de la Planificación}

Existe un Diseño Universal para el Aprendizaje sugerido por (CAST, 2008), basado en los siguientes tres principios:

\subsubsection{Primer principio:}

Proporcionar múltiples medios de Presentación y Representación: es la combinación de tres modalidades que se alternan en función de los propósitos que se quieran alcanzar y que a continuación se mencionan:

a. Modalidades alternativas para favorecer la percepción de la información (visual, auditiva): utilizar en la presentación de las clases materiales de apoyo para conectarse con esta modalidad, tales como mapas mentales, gráficos, figuras, diagramas, entre otros.

b. Modalidades alternativas de lenguaje y simbolización de la información (apoyos de símbolos dentro de un texto): se utilizan emblemas e insignias para distinguir o acentuar el discurso.

c. Modalidades alternativas para favorecer la comprensión: es un principio que posibilita fomentar la capacidad de análisis, el cual puede realizarse mediante planteamientos distintos o lluvia de ideas.

\subsubsection{Segundo principio:}

Proporcionar múltiples medios de Ejecución y Expresión. Este principio se corresponde con las diversas actividades que ofrezcan las manifestaciones artísticas o culturales que$$
58
$$

se encuentren inmersas en la creatividad e innovación para trasmitir los conocimientos mediante:

a. Funciones ejecutivas: promueve acciones eficaces mediante técnicas adecuadas en la praxis educativa.

b. Acción física: fomenta las actividades que alejan de la rutina al innovar con actividades recreativas que brinden esparcimiento mientras se aprende tanto dentro como en espacios abiertos.

c. Habilidades expresivas y la fluidez: coadyuva a mejorar el lenguaje y desarrollar claridad vocal con trabalenguas, deletreos, lecturas y otros.

\subsubsection{Tercer principio:}

Proporcionar formas alternativas de Compromiso. Se trata de incentivar la corresponsabilidad en el proceso de aprendizaje combinando diversas de participación:

a. Concitar el interés. Son opciones para motivar la atención de los estudiantes.

b. Apoyo al esfuerzo y la persistencia. Es el acompañamiento constante que se les otorga a los participantes y el reconcomiendo a su esfuerzo con gestos y palabras que refuercen e incentiven.

c. Control y regulación de los propios procesos de aprendizaje. Se entiende como el proceso de seguimiento, valoración, observación, intervención y registro que debe estar contemplado en el criterio de evaluación.

Todos los principios anteriores, deben tomarse en cuenta 59 
al planificar los temas de clase, por cuanto se establecen además las técnicas que se utilizaran en cada una de las estrategias para ser aplicadas en el desarrollo de las destrezas docentes, en la concepción de la guía que orientará los procesos de ejecución contemplados en los planes de clase.

\subsection{Diseño curricular y articulación de contenidos}

Dentro de las políticas educativas, el estado debe en primer lugar propender una educación acorde a los acuerdos alcanzados en las conferencias mundiales realizadas por la UNESCO y otras instancias internacionales interesadas en la evolución educativa, dado que son estas instituciones las que demarcan la línea de acción a seguir para unificar los criterios educacionales.

En segundo término, se estima que la educación de un país corresponde a una intencionalidad y bajo esa premisa se circunscribe el diseño de las líneas fundamentales de una política cultural, educativa y social que funge a modo de órgano rector de la formación, como premisa para cimentar las bases pedagógicas de una nación.

En un sentido amplio, tras abarcar tales lineamientos que emanan de instancias nacionales e internacionales, el currículo se adapta a la realidad y necesidades de un país al prescribir el proyecto educativo general que abarque todos los sistemas de estudio sustentados con sus referentes filosóficos, sociológicos, epistemológicos, psicológicos y didácticos. (Ver imagen 1)

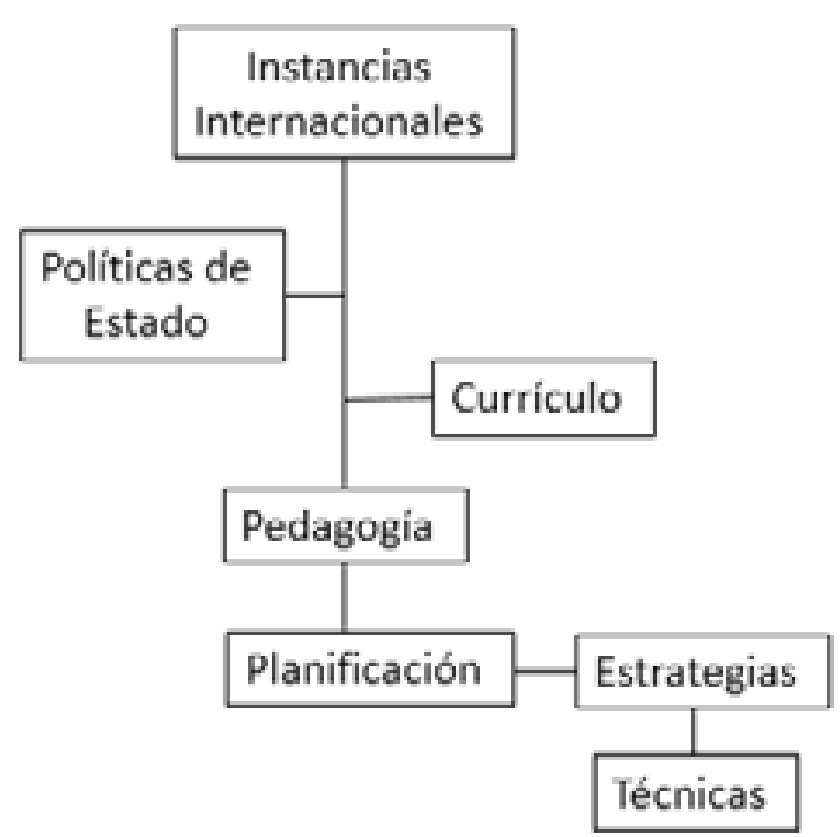

Fuente: Elaboración propia.

El currículo, es un lineamiento teórico-práctico que orienta los procesos de intervención pedagógica para la formación integral del educando dentro de una propuesta de acción educativa determinada. Por ello, el currículo es también una propuesta pedagógica para la enseñanza y el aprendizaje, que presume el trabajo pedagógico desde un ambiente que enmarca los espacios socioculturales. (Mendo 2006:8).

En ese orden, el currículo encierra objetivos y finalidades específicas, estructurado por una organización formal de los propósitos y programas de estudio que describe las metas educativas dentro de los contenidos a ser desarrollados en 
una institución educativa; la cual señala la dirección que debe tomar el acto de aprendizaje en correspondencia con las leyes y reglamentos.

Desde el momento en el que se construye el currículo, participan personas vinculadas a la educación y profesionales altamente calificados, quienes van creando y diseñando la esquematización de su estructura, a través de la toma de decisiones convenientes a los temas de estudio para la formulación del contenido que finalmente se diseñara en el aula de clases y los ambientes de aprendizaje en específico.

En ese ámbito, el diseño curricular se plasma como parte dimensional del currículo en el que se plasma la metodología, acciones y resultados, en términos de cumplir tareas como diagnóstico, modelación, estructuración, y organización de los proyectos curriculares para llevarlos a cabo en feliz término y que estos se orienten al aprendizaje eficaz de los educandos. Fernández (2017).

De allí se desprende la importancia que tiene propender un currículo que enlace contenidos programáticos inmersos en los aspectos necesarios para la correspondencia entre todas las políticas educacionales orientadas a conectar todos los niveles de la enseñanza, desde la primaria hasta la universitaria y la de posgrado, asegura una concepción pedagógica del aprendizaje como proceso formativo participativo, gradual y sistemático. Brito (2008: 41). Esto, con la finalidad de dirigir el proceso de definición de técnicas coherentes a las estrategias que se plasmen en la planificación y que a su vez se sustentes en el currículo.

\subsection{Delineando un Instrumento adecuado}

Diseñar un instrumento de planificación requiere recrear en un papel de trabajo los procesos y subprocesos que definan los estándares de acción, seguido por una secuencia lógica que promueva las actividades que los estudiantes van a ejecutar bajo la dirección educativa del docente.

Para ello, el docente debe propender las estrategias dentro de una relación acertada con respecto a las técnicas, de modo que se evidencie su coherencia en la aplicación de las mismas, sin aislar los fines educativos para lo cual se están implementando. Este ejercicio compone una estructura que engloba los siguientes elementos:

a) Identificación de la institución: En este apartado se deben colocar los logos e identidad educativa.

b) Periodo: Es el lapso de tiempo comprendido dentro del calendario académico en el que se van a ejecutar las clases.

c) Objetivos: Son las metas ampliadas que se desean alcanzar bajo las que se circunscribe el proceso que implica desarrollar el plan general. Los objetivos específicos se detallan en profundidad.

d) Sinopsis del contenido: Es la síntesis de las unidades temática, donde se mencionan los aspectos conceptuales, procedimentales y actitudinales que se persiguen.

e) Estrategias: Engloba la secuencia de pasos que se ejecutan para la optimación y regulación de procesos cognitivos afectivos y psicomotores. De allí emergen las técnicas que se deben utilizar, así como los recursos pertinentes. 
f) Evaluación: Es el momento de dar la ponderación en los niveles de conocimiento alcanzados mediante un instrumentos para tal fin.

g) Medidas de atención a la diversidad: Son las formas de acción que debe adaptar el docente para la dedicación y el cuidado de casos particulares a niños con necesidades educativas especiales y compromisos cognitivos.

Imagen 21. Instrumento de Planificación.

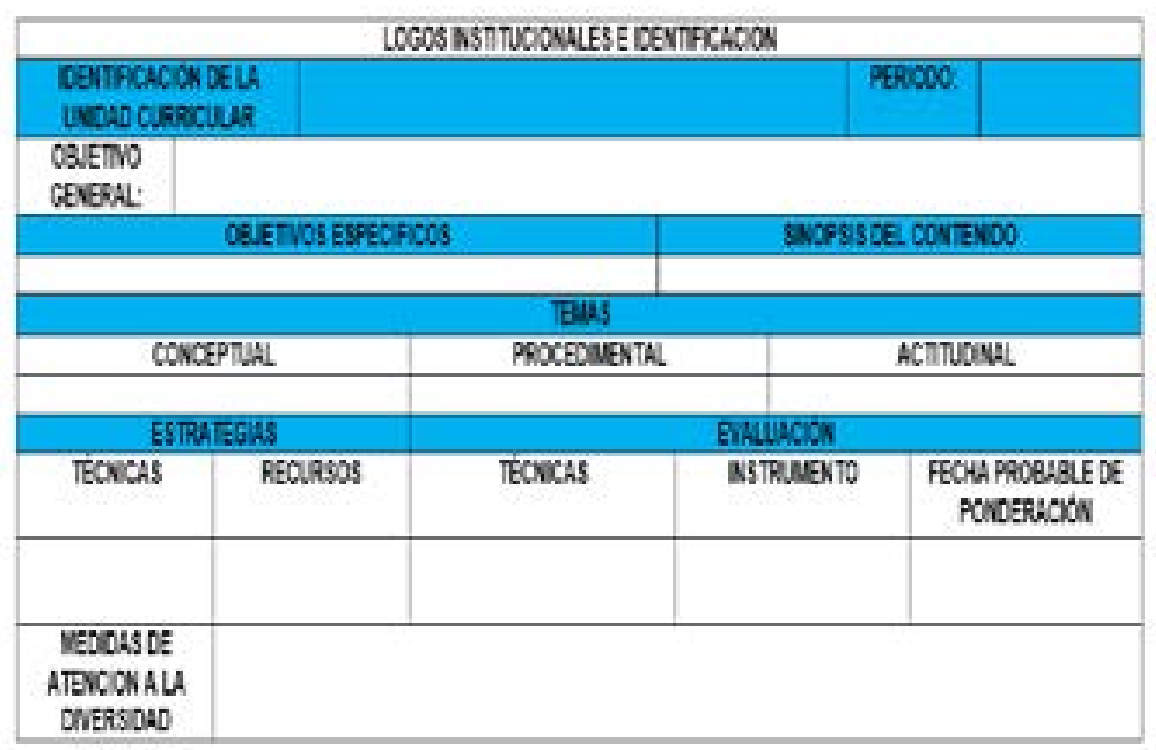

Fuente. Elaboración propia.

64

\section{5. ¿Qué hacer si la planificación no arroja los resultados deseados?}

Dada la complejidad del ser humano y las condiciones psicológicas y sociales que parten de las particularidades individuales de cada persona, es posible que dentro del aula de clases, no todos los alumnos alcancen los objetivos propuestos en la planificación diseñada por el docente. Si se presentan estos casos, lejos de aislar al estudiante se le debe atender con una adaptación de las técnicas, no necesariamente se cambia la estrategia.

A la luz de las anteriores consideraciones, urge la necesidad de integrar a los estudiantes de manera consensuada, involucrar a la familia, establecer acuerdos de adaptación, innovar con estrategias didácticas y metodológicas que se inclinen hacia el aprendizaje significativo y lúdico con técnicas que correspondan al modelo instruccional y a los propósitos de aprendizaje.

En este proceso de direccionalidad del aprendizaje y educación, el docente debe fundamentarse en el diálogo freireano de la dialogicidad y la problematización con la asunción de sus destrezas, fortalezas intelectuales, humanas pero también con el reconocimiento de sus propias limitaciones; de manera que se interactúe bidireccionalmente al verse como sujeto de aprendizaje igual que el educando, donde se eduquen ambos. Del Granado (2008:87).

En el marco de una nueva pedagogía en donde se desarrollen las técnicas, coherentes que se sujeten a las necesidades de los estudiantes en forma reflexiva, los estudiantes tienen que ser 
capaces de proponer sus propios métodos para transformar su realidad y que no se sientan sometidos a una estructura rigida, sino que por el contrario les ofrezca un espacio de flexibilidad sin salirse de los propósitos de enseñanza. 


\section{CAPÍTULO III \\ DEL DIAGNOSTICO PEDAGOGICO A LA ACCION PEDAGOGICA}

La atención integral de los educandos es fundamental en el ambiente de aprendizaje, por ello se debe conocer en profundidad a todos los participantes que hacen vida en ese entorno, de manera que se pueda identificar en ellos desde sus características físicas hasta sus condición psicopedagógica de allí surgirán elementos que son esenciales para la construcción de las estrategias y técnicas específicas.

Es una investigación cualitativa sobre los rasgos de la personalidad del estudiante, donde se toma en consideración las habilidades y potencialidades de los alumnos de acuerdo al estilo de aprendizaje particular, cuyo objetivo es describir, clasificar, predecir y explicar el comportamiento de un sujeto dentro del marco escolar en opinión de Buisán y Marín (2001:63). En esta caracterización, se establecen las condiciones específicas de los niños para observar, precisar y atender situaciones que ameriten atención oportuna con la participación de todos los actores institucionales, del personal, los docentes, la familia y los miembros de la comunidad educativa en general.

Parra Arriaga (2015:63), como ejercicio de aproximación entre docentes y alumnos, implica el descubrimiento de aspectos cognoscitivos, actitudinales y aptitudinales tanto positivos como negativos del grupo y de cada uno de sus integrantes, dado que en él se determinan los problemas que afectan el desarrollo y aprendizaje de los infantes, con la firme 
intención de obtener la información necesaria para accionar las herramientas adecuadas.

De tal modo que este proceso inicial es una herramienta metodológica que permanece de forma constante en un plano de contraste entre lo empírico-operativo y teórico-conceptual. El resultado que arroje el diagnóstico, se entiende como un mero reflejo de la situación particular que evidencia en sí mismo los aspectos inherentes al tratamiento especial de técnicas adecuadas que ataquen los momentos críticos acaecidos en la realidad diaria de un ambiente de aprendizaje.

\subsection{Tipos de Diagnostico}

Conocer la tipología del diagnóstico se considera de suma importancia por cuanto permite al docente ubicarse en el estatus cognitivo en el que se encuentra el niño. Según Granado (2003), el diagnóstico se divide en:

a) Clasificador: Es cuando se aplican las primeras pruebas de inteligencia, cuyos resultados deben revelar cómo se encuentra el niño con respecto a sus compañeros de clase con la finalidad de llevar un registro organizado y así tomar las medidas de atención por grupos a fin de reforzar su rendimiento educativo.

b) Preventivo: Es advertir anticipadamente posibles problemas de compromisos cognitivos, desajustes emocionales o sensomotores para poder trazar la estrategia de atención adecuada.

c) Modificar o correctivo: Es el informe que se realiza sobre el estudiante, una vez conocidas las causas de su problema y realizada la atención adecuada que ajuste y transforme el comportamiento del infante.

Imagen 22. Tipos de diagnostico

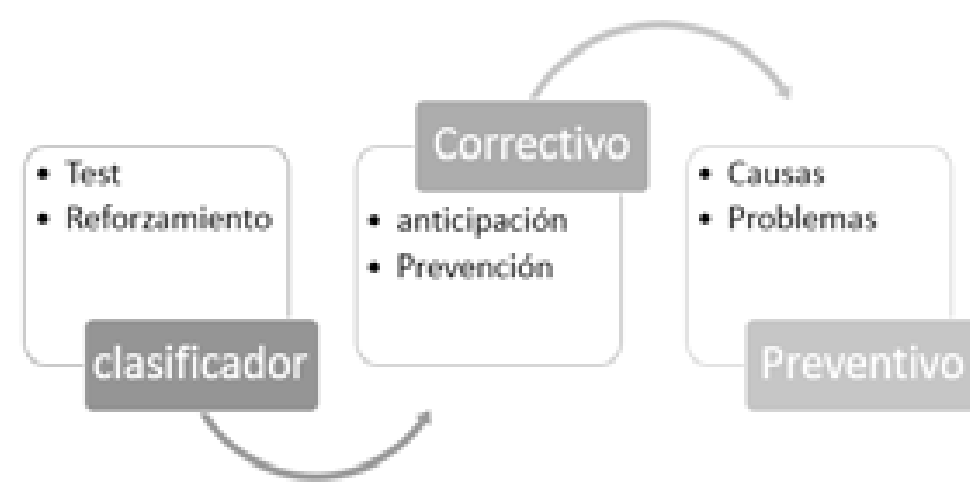

Fuente: Elaboración propia a partir de Granado (2003).

\subsection{Objetivos del diagnóstico pedagógico.}

Con el fin de orientar las estrategias correctivas, el diagnóstico se enfoca en las modalidades que a juicio de Álvarez (1984), alinea los objetivos generales, a saber:

a) Preciación: Es la comprobación sucesiva del niño en función de los propósitos planificados con anterioridad. Ej.: relaciones interpersonales o condición psicosomática.

b) Pronóstico: Es el momento en el que se identifican los factores que influyen directamente en el aprendizaje y merman la capacidad de desarrollo del niño. Ej.: familias disfuncionales, problemas de adaptación.

c) Pedagogía correctiva: Son las medidas que se adaptan de acuerdo a las necesidades del alumno en aras de mejorar 
su condición. Ej.: Estrategias de solución con base a las características encontradas.

Imagen 23. Objetivos del diagnóstico

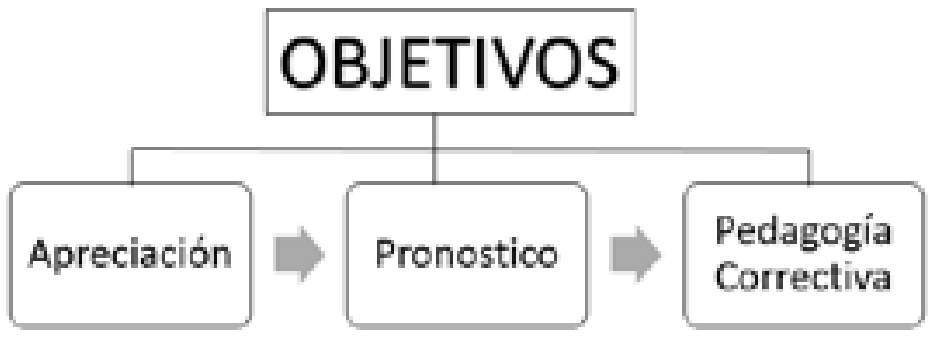

Fuente: Elaboración propia (2019)

\subsection{Indicadores de algunas condiciones}

Algunas de las condiciones que se pueden encontrar en el diagnóstico son las siguientes: somática, afectivo, senso-perceptivo, motora, senso-motora, comunicativa, de pensamiento o normativa, lesiones cerebrales afectaciones gráficas por algún tipo de enfermedad, problemas emocionales, retrasos, problemas en las funciones básicas, dislexias, de adaptación, desajuste, psicopatologías, alteraciones, entre otros.

\section{Imagen 24. Modalidades del Diagnóstico}

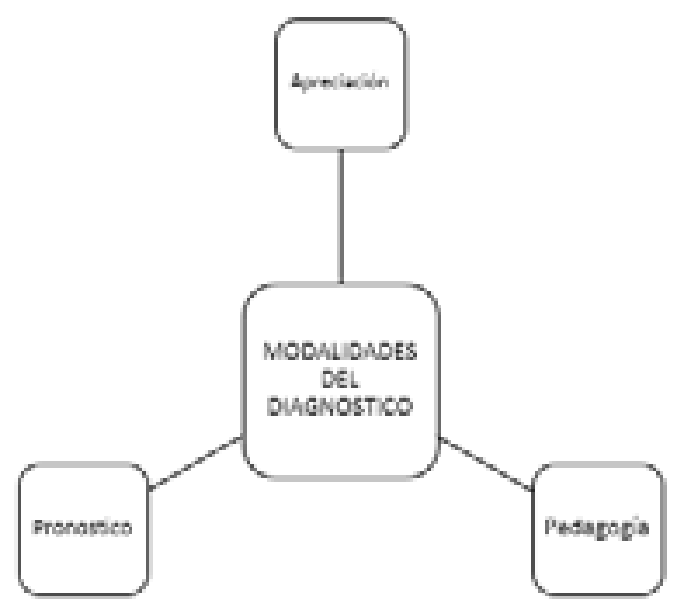

Fuente: Elaboración propia a partir (2019)

\subsection{Proceso investigativo y descripción de las situaciones problémicas}

Entre los pasos a considerar en un estudio diagnóstico se tiene: conformación de un equipo multidisciplinario, revisión de investigaciones previas, diseño teórico y metodológico del instrumento o test que se va a aplicar, preparación y validación de los instrumentos con expertos en la materia, aplicación de la prueba diagnóstica, procesamiento y análisis de la información, presentación de informe a los interesados y atender las recomendaciones. 
El propósito principal de este proceso, es obtener información oportuna que le permita al docente buscar herramientas útiles para buscar alternativas pertinentes de cara a la modificación de las condiciones generadoras de aquellas situaciones que impidan o retrasen el aprendizaje de los niños mediante las correspondientes acciones preventivas o potenciadoras. Arriaga (op.cit)

Para la realización y aplicación del diagnóstico, es importante tener en cuenta que deben cumplirse las siguientes etapas:

a) Recogida de información

b) Análisis de la información

c) Valoración de la información (como fiable/válida) para la toma de decisiones,

d) La intervención mediante la adecuada adaptación curricular, y

e) La evaluación del proceso diagnóstico.

Desde esta perspectiva, se considera supremamente importante que el educador conozca a sus participantes; y para ello debe apropiarse de la labor de atención especial, con la finalidad de poder ofrecerles el apoyo necesario a las necesidades educativas especiales en función de garantizar la diversidad, la coparticipación y la integración de todos por igual.
Imagen 25. Pasos del Diagnóstico

\section{Recogida de Información}

\section{Análisis de la} información

\section{Valoración de la información}

\section{Intervención adecuada}

\section{Evaluación del \\ Diagnostico y \\ su proceso}

Fuente: Elaboración propia a partir de Arriaga (2008).

\subsection{Dimensiones}

Como parte de las variables que deben considerarse, se encuentran tres dimensiones, que son: la biológica, la psicológica y la cognitiva, según García (1995); por cuanto representan aspectos inherentes al desarrollo biopsicosocial del ser humano y aportan gran significancia en los estudios que se realizan mediante el diagnóstico.

a) Dimensión Biológicas: Es un estudio detallado que indaga la historia prenatal y postnatal, el desarrollo del lenguaje y motor, problemas de salud en general propio y familiar, así como la madurez biológica y el crecimiento. 
Imagen 26. Dimensión biológica del diagnóstico

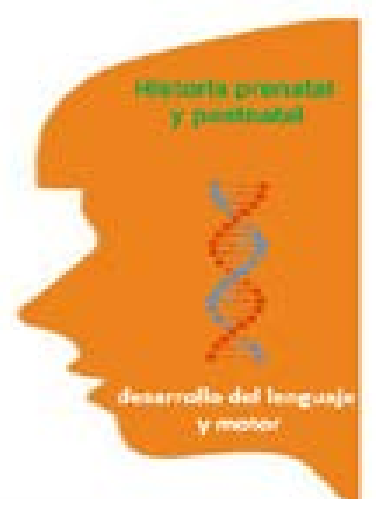

Fuente: Elaboración propia

b) Dimensión Psicológica: De acuerdo con García (1995), Son las actitudes que se dirigen hacia los intereses y motivaciones, cuyo influjo puede anular, reducir, potenciar o transformar sus aptitudes en dependencia a las mismas.

Imagen 27. Dimensión psicológica del diagnóstico

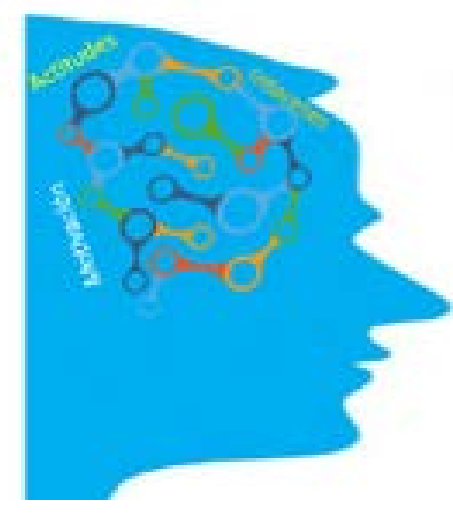

Fuente: Elaboración propia (2019) c) Dimensión Cognitiva: En este ámbito, García (1995), afirma que el diagnóstico persigue la pretensión de caracterizar al estudiante para determinar las habilidades que domina sobre los objetivos, contenidos curriculares o competencias ante los objetivos trazados.

Imagen 28. Dimensión biológica del diagnostico

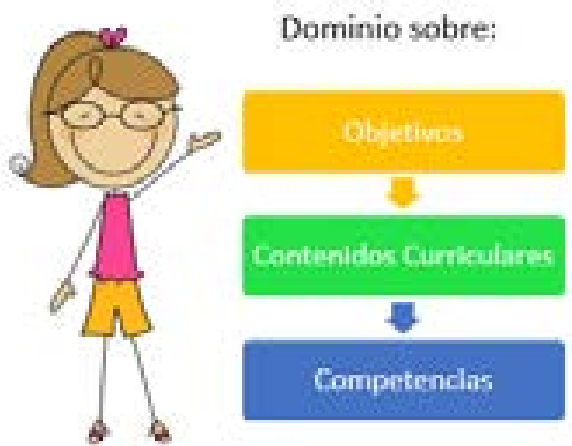

Fuente: Elaboración propia a partir del kit familia palito (2019)

\section{6. ¿Cómo abordar las técnicas para casos particulares?}

De modo más específico, y para dar respuestas a las posibilidades de aprendizaje de todos los alumnos, el hecho de conocerlos bien contribuye con la construcción de un aprendizaje óptimo, al organizar las experiencias pedagógicas más amenas, participativas y en correspondencia con los hallazgos, de modo que se pueda ofrecer variedad de actividades que permitan trabajar los contenidos con diferentes grados de complejidad y así garantizar el conocimiento de todos por igual en un cuadro 


\section{de integración.}

En el marco de una educación inclusiva, si llegare el caso de que las estrategias no arrojan los resultados deseados dentro de las particularidades que se presenten, el docente debe ofrecer la posibilidad de que los alumnos elijan entre distintas actividades y decidan la forma de realizarlas orientado hacia el cooperativismo y participación.

Otra de las opciones es brindar espacios para que realicen prácticas de lo aprendido en aras de favorecer su autonomía y organizar el ambiente de aprendizaje para desarrollar las estrategias, ajustar las normas y hacerles saber a los demás integrantes del salón que se debe trabajar en un clima de respeto y armonioso para evitar las burlas y el bullyng que tanto afecta emocionalmente a los niños.
Imagen 28. Diagrama de flujo para el abordaje de Técnicas particulares.

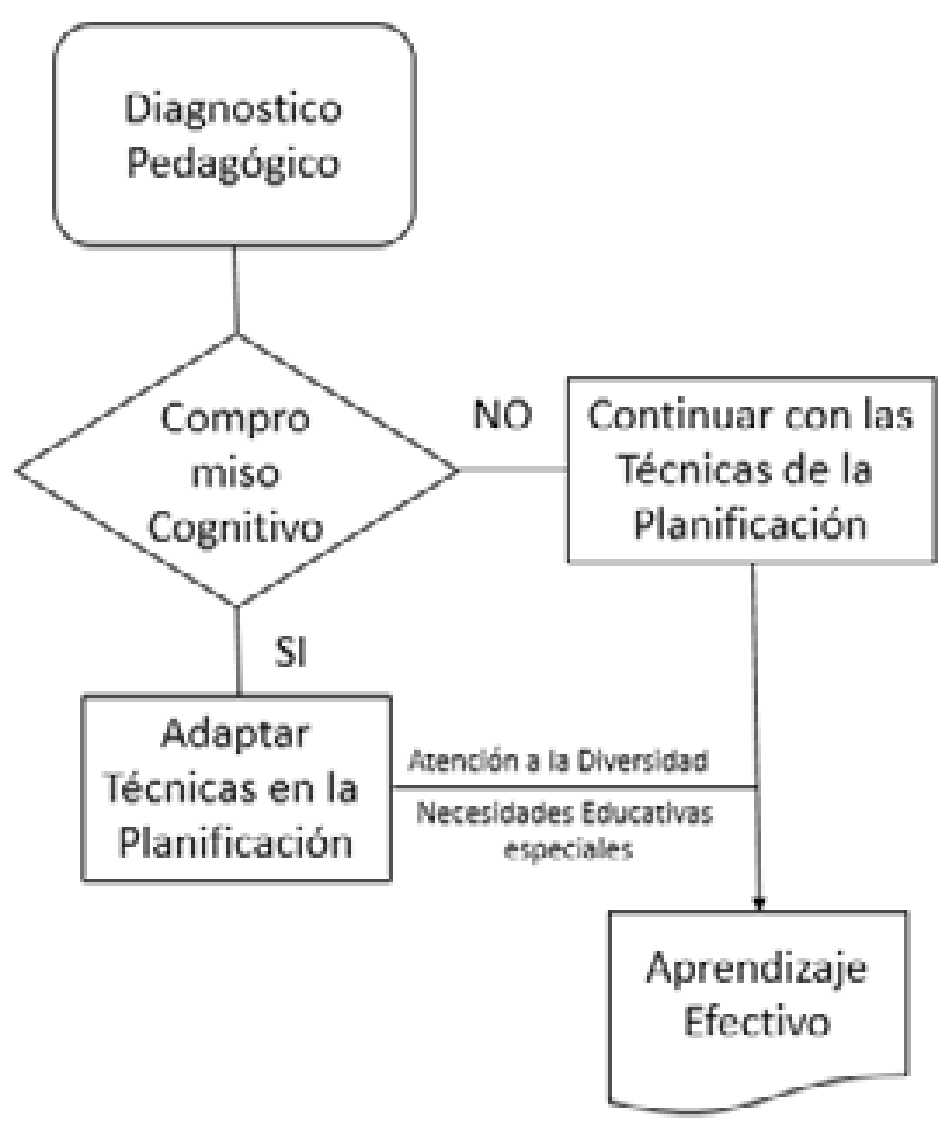

Fuente: Elaboración propia 


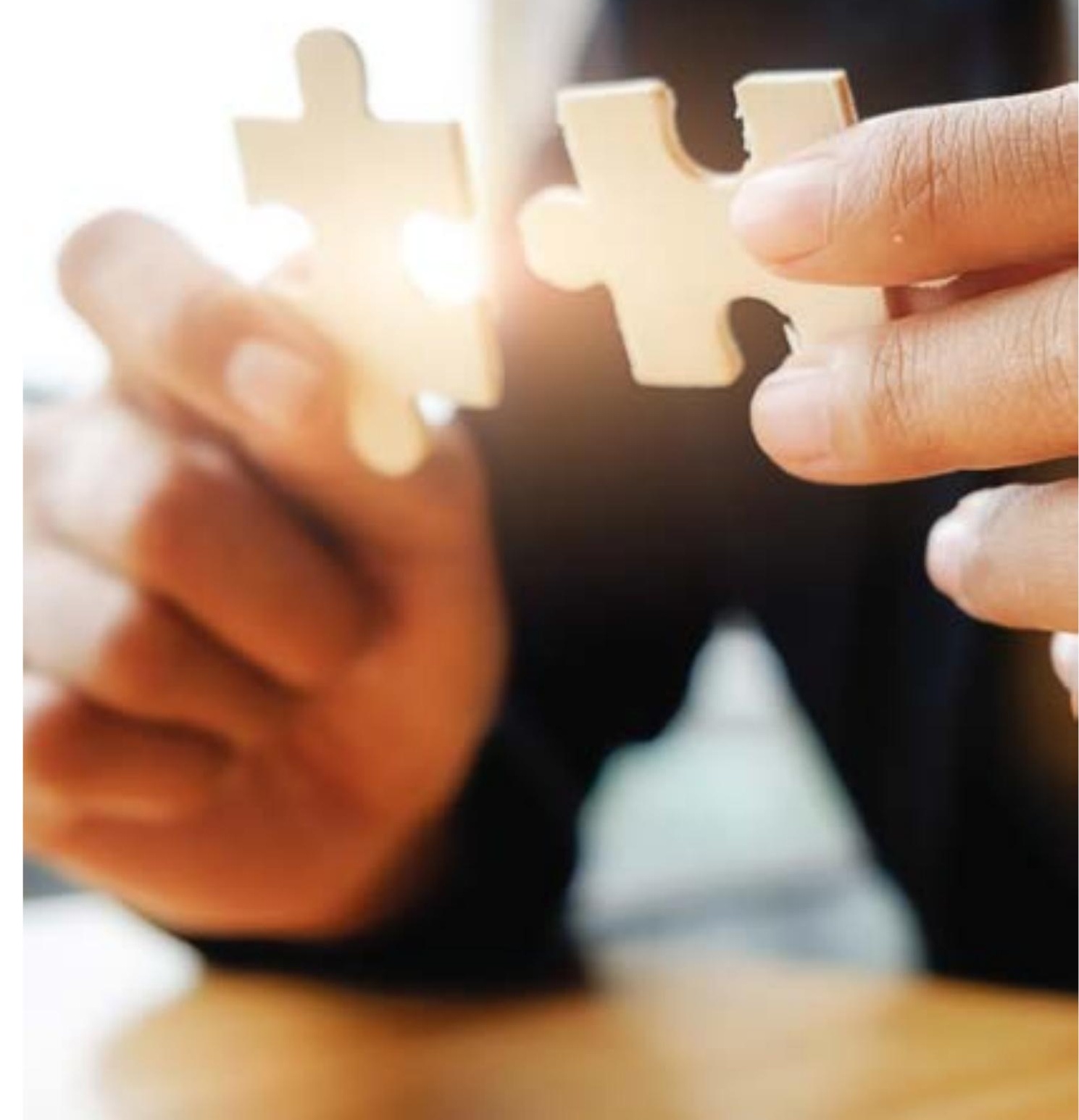




\section{CAPÍTULO IV}

\section{EL ROL DEL DOCENTE COMO MEDIADOR DEL APRENDIZAJE}

Quien diga que ser docente es una profesión corriente y fácil, definitivamente no sabe lo que dice. Un docente debe formarse y estudiar a diario, preparar las clases, dar ejemplo con su puntualidad, modales y comportamiento, hablar durante cuatro horas o más, bregar con la personalidad de sus alumnos, además de atender sus necesidades fisiológicas, psicológicas y de aprendizaje, elaborar el material de apoyo, ser creativo, evaluar las asignaciones, entre muchas tareas más.

Todas esas actividades solo se pueden realizar con vocación de servicio, formación y un compromiso inmensurable que hacen visibilizar las fortalezas y virtudes que su quehacer diario y que exige además entrega, mística, responsabilidad, calidad y disciplina, de abnegación y acción positiva hacia la aprensión de valores.

De acuerdo a estas ideas, vale la afirmación de García y cols. (2012), quien expresa que convertirse en buenos enseñantes implica, atreverse a renovar, a desarrollar el pensamiento, asumiendo propuestas creativas e innovadoras. Es dar un paso siempre adelante con la firme convicción de enseñar y transformar al niño en un hombre de bien.

En consecuencia, los docentes deben actualizarse académicamente, dado que hay una relación mutua entre sus conocimientos, el cómo los transfiere y el aprendizaje de los 
alumnos que están bajo su cargo, o lo que es lo mismo: de su preparación depende el futuro de los ciudadanos que está formando, por lo cual tiene una gran responsabilidad al asumir el reto de enseñar.

El papel del maestro es promover el conocimiento, orientación permanente, contribuir a la formación integral de ciudadanos, conducir el proceso educativo con habilidades y destrezas, ser garante del aprendizaje como misión altruista. Todo ello como parte de su gestión docente dentro del aula y su alto compromiso vocacional que debe desarrollar.

\subsection{Lo ético y lo estético en el acto pedagógico}

Partir de los valores para educar es respetar la naturaleza del ser humano, quien se desenvuelve en todos los aspectos inherentes a su vida con una carga de "componente y eje axiológico como especificidades, para promover los procesos sociopsicológicos de cambios y transformaciones cualitativas, tal y como sostiene Lamus (2011). Detalles que describen la esencia de su pensamiento educacional y compromiso.

En ese sentido, resulta interesante mencionar la afirmación de Cruz y Miranda (2009:4), cuando sustentan que:

Todo maestro se pregunta cómo hacer para educar correctamente. He ahí un primer asunto que no se refiere sólo a problemas didácticos, metodológicos generales o psicológicos, sino a una racionalización superior que pondera una determinada concepción de la vida. Se encuentra en el marco de estas reflexiones además del cómo, el para qué, lo que precisa la necesidad del examen de las finalidades educativas en las que se enmarca la práctica pedagógica concreta en los ámbitos axiológico, epistemológico, lógico y metodológico conceptual en general.

En razón de la anterior cita, es imprescindible que en todos los centros educativos, los docentes se comprometan a cultivar una influencia positiva dirigida a fomentar condiciones concretas de aprendizaje en general, como fruto de la interrelación entre las aptitudes y actitudes valorativas, mediante el desarrollo transversal de un eje estético lúdico donde se practique la danza, las artes plásticas o la musical, como una herramienta que permita llevar a cabo la devolución del conocimiento, desarrollado de manera didáctica y amena y a su vez contribuya con el crecimiento personal en función de sus necesidades, motivaciones y vivencias con espíritu reflexivo y sensible.

Por lo tanto, la belleza, el arte, la creatividad, el respeto, la empatía, lo verdadero, lo correcto y lo bello debe ponerse en práctica, no como criterio estático sino como criterio vivo, hacerlo propio y mantenerlo en construcción permanente. Garnier (2008:126), hecho que facilitará la comprensión y la sensibilización de los saberes integrales del individuo.

\subsection{Empírea y praxis pedagógica}

Las experiencias obtenidas por los docentes durante sus prácticas profesionales, le permiten enfrentarse al manejo de situaciones de cara a la realidad que se encuentran en el aula de clases, la cual es muy compleja dada la diversidad de pensamientos y comportamientos. He ahí donde consiguen 
el verdadero sentido del ejercicio docente que consolidará su profesión.

Es así, como Knowles (1982:34), exterioriza que "la experiencia previa constituye una base de sustento para el nuevo aprendizaje el cual se consolida en forma más significativa. Además, crea un adecuado contexto para la adquisición de conocimiento y habilidades". En ese sentido, se incorporan nuevas técnicas y estrategias in situ, que demuestran el contraste con la labor educativa natural, la cual se adquiere para la aplicación de destrezas y se encaminan de la empírea a la praxis de campo en momentos indivisibles dentro de un mismo proceso.

Por eso, indiscutible es señalar a Freire (1979: 5), quien manifiesta que "la praxis teórica es lo que hacemos desde el contexto teórico, cuando tomamos distancia frente a la praxis que se ha realizado o se está realizando en un contexto concreto con el fin de clarificar su sentido". Esas digresiones, conducen la dialéctica necesaria que deben irrumpir en el docente cuando se encuentran la experiencia y la práctica: no como una antítesis, sino más bien como una fusión que respete lo vivido, el devenir histórico, la carga socio emocional de cada quien.

Imagen 29. Empírea vs praxis

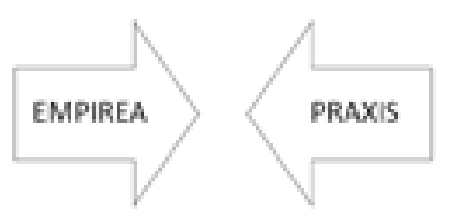

Fuente: Elaboración propia (2019)

\subsection{Desarrollo de competencias educativas}

Consiente de la importancia que tiene brindar a los escolares una educación de calidad, el docente debe propender a la adquisición y desarrollo de una serie de prácticas adecuadas que optimicen su ejercicio profesional y técnico en el ambiente de aprendizaje, las cuales potenciarán su gestión educativa, sus capacidades, destrezas y mejoramiento profesional, lo cual tributa en el desempeño aptitudinal del mismo, en la transferencia del conocimiento hacia el estudiante.

Interactuar con tales habilidades podría garantizar la mejora de los factores que regulan la educación y la conducción eficaz del aprendizaje. Aliendres (2012:25-38), las competencias que debe alcanzar el docente se describe en la siguiente guisa:

\subsubsection{Las competencias básicas:}

Están caracterizadas por la formación personal e integral que se encuentran intrínsecamente ligadas a las personas, vale decir: su dimensión biológica, intelectual, social e intrapersonal

\subsubsection{Competencias comunicativas:}

Es la apropiación y dominio del uso del lenguaje oral y escrito para trasmitir la información en la transferencia del conocimiento para que el mensaje llegue en forma clara y contundente.

\subsubsection{Competencia de autogestión de proyecto de vida:}

Es la asunción de retos y desafíos con respecto a su propia autorrealización personal y la forma en que se relaciona con el entono. Implica el manejo de sus creencias y valores. 


\subsubsection{Competencias referidas a las nuevas tecnologías de la información y la comunicación:}

Es el conocimiento y la capacidad de manejar herramientas computacionales, hardware, software, procesar textos, hojas de cálculos, presentaciones, internet y saber tener acceso a la web 3.0

\subsubsection{Competencia de afrontamiento:}

Consiste en la adaptabilidad, resistencia y manejo de situaciones fortuitas que llegan de forma imprevistas sin que ello signifique que pierda su enfoque.

\subsubsection{Competencia de liderazgo:}

Se relaciona con la capacidad ser proactivo, motivador, comprometido y sociable, capaz de ser modelo que inspire a sus estudiantes.

\subsection{Competencias genéricas}

Para Corominas (2001), se relacionan con

1) El aumento de empleabilidad

2) Favorecer la gestión, consecución y conservación del empleo

3) Permitir la adaptación a diferentes entornos laborales

4) Pueden desarrollarse en cualquier ocupación

5) Se adquiere mediante procesos sistemáticos de enseñanza y aprendizaje

6) Su adquisición y desempeño puede evaluarse de manera rigurosa.

\subsubsection{Emprendimiento, gestión de recursos trabajo en equipo y resolución de problemas:}

Es el desarrollo de propuestas sustentadas en los objetivos y metas organizacionales, así como en las demandas externas relacionadas con proyectos productivos innovadores de mejoramientos de las condiciones de trabajo.

\subsubsection{Las competencias específicas:}

Hace referencia a cinco áreas en las cuales el docente despliega su actividad personal, pedagógica, institucional, relaciones interinstitucionales y tutorías.

\subsubsection{Calidad educativa:}

Representa toda actividad que se vincule a la planificación, la organización del trabajo, la selección de los contenidos, el material de apoyo, la coordinación, la revisión de los procesos y el sistema de evaluación. 


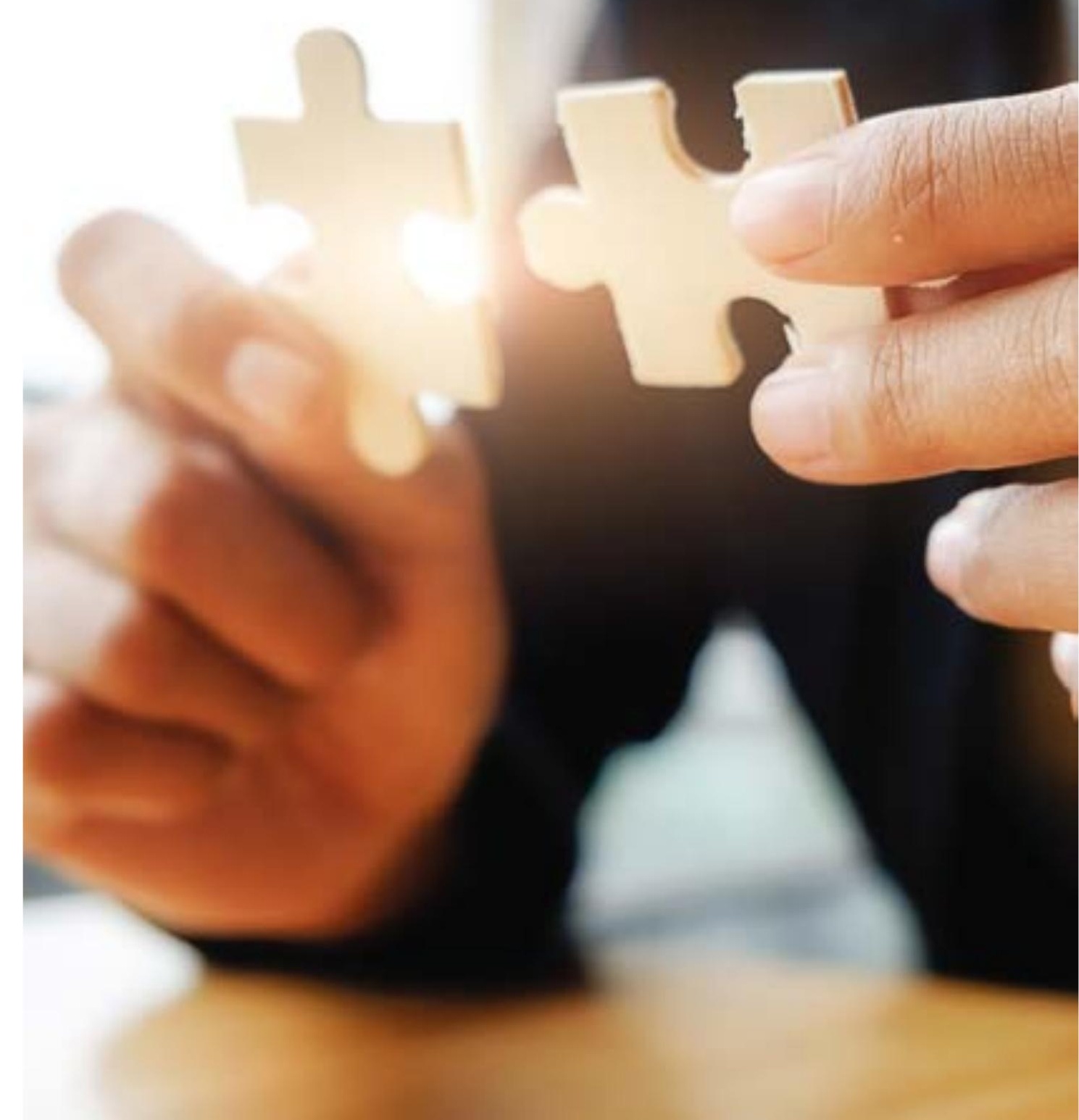




\section{CAPÍTULO IV}

CONSTRUYENDO EL APRENDIZAJE A TRAVES DEL CONOCIMIENTO DE TECNICAS APROPIADAS

Con respecto al grupo de técnicas para la enseñanza, Losada, Montaña y Moreno (2003, pp. 25-85) detallan la siguientes técnicas

a) Expositiva: Es aquella cuyo propósito persigue la transmisión de conocimientos, a fin de que los receptores puedan relacionar crítica y reflexivamente los diversos conceptos.

Imagen 29. Técnica expositiva.

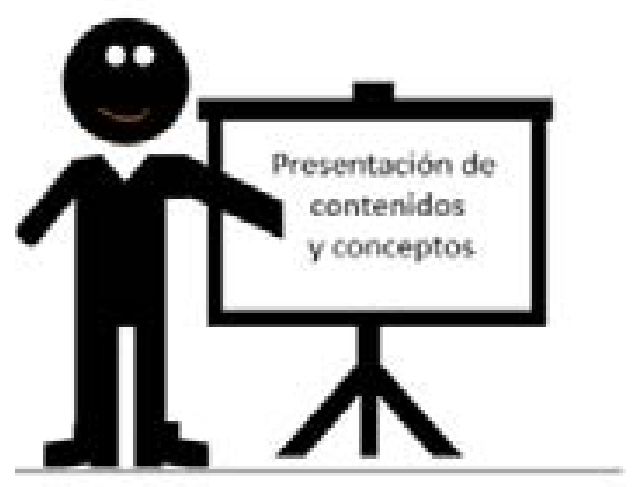

Fuente: Elaboración propia (2019)

b) Del interrogatorio: consiste en indagar con profundidad sobre los planteamientos expuestos, mediante interrogantes que cuestionen un proceso. 
Imagen 30. Técnica de Interrogatorio

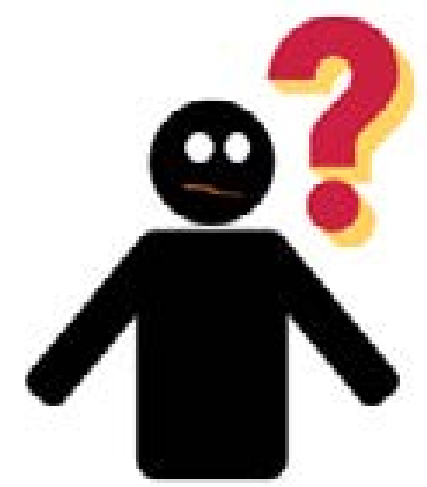

Fuente: Elaboración propia (2019)

c) Del diálogo: Es la interacción entre dos personas que buscan respuestas sobre un tema en común.

Imagen 31. Técnica del Diálogo.

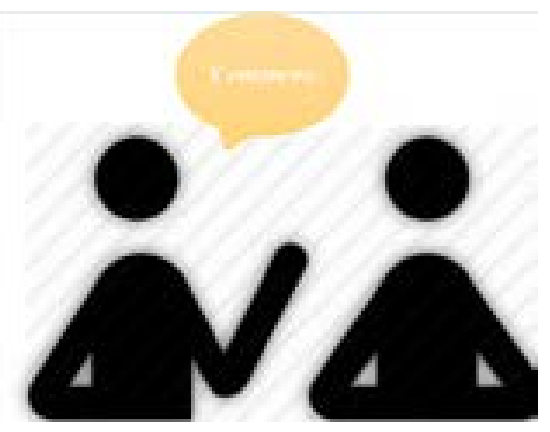

Fuente: Elaboración propia (2019) d) De la discusión: Es una actividad parecida al desarrollo de una clase, donde participan todos, pero dirigida por estudiantes, donde uno de ellos guía la hilaridad del discurso.

\section{Imagen 32. Técnica de la discusión}

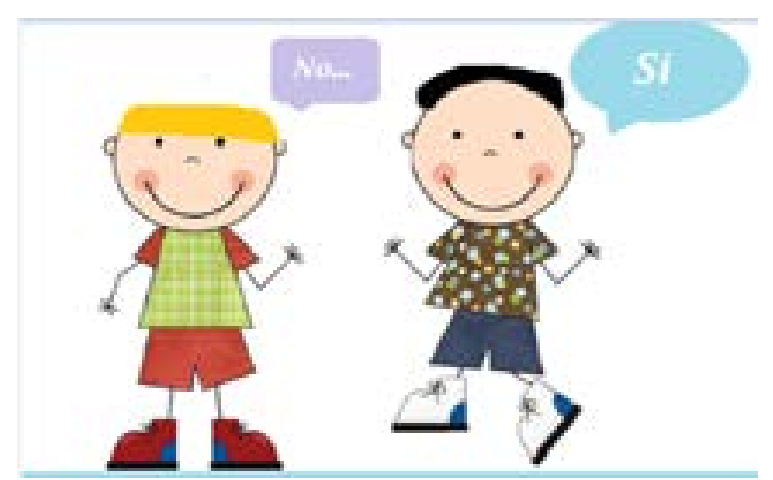

Fuente: Elaboración propia (2019)

e) De estudio de casos: Es el tratamiento comprehensivo de una situación dada dentro de un contexto y personas específicas, que complejiza su análisis.

Imagen 33. Técnica de estudio de casos

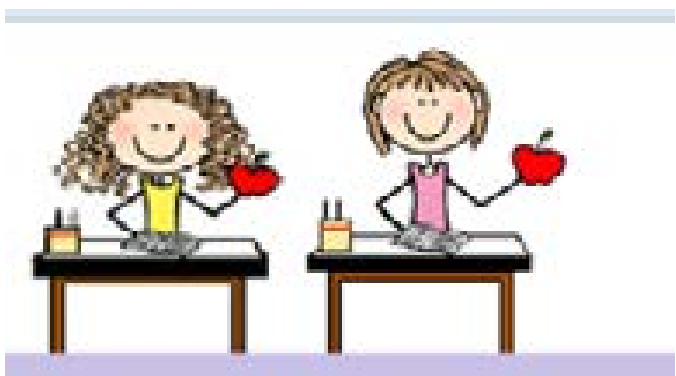

Fuente: Elaboración propia (2019) 
f) De problemas: La problematización es una condición fundamental del aprendizaje activo, en el que los alumnos son actores principales, pues aprender es un proceso llevado a cabo, en primera persona, por el sujeto, mediante la acción sobre los objetos de aprendizaje y el concurso de diversas dimensiones del aprendiz (volitivas, emocionales, relacionales, cognitivas, etc.

Imagen 34. Técnica de problemas

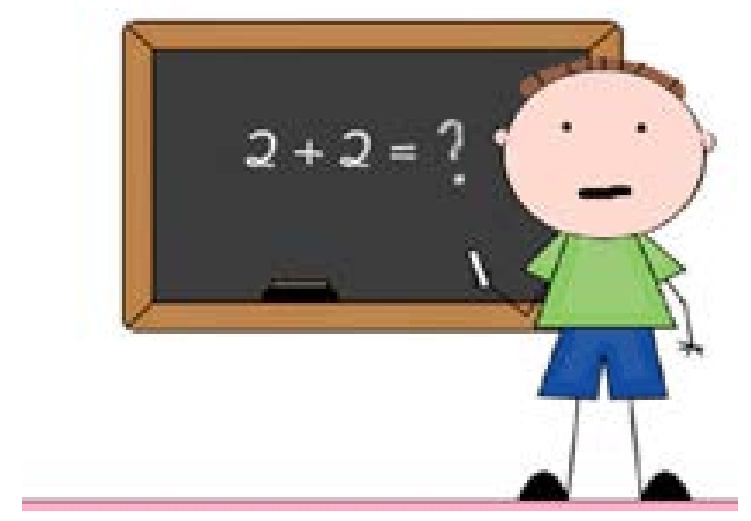

Fuente: Elaboración propia (2019)

g) De la demostración: Es la exposición de un proceso para certificar su funcionamiento y operatividad

\section{Imagen 35. Técnica de la demostración}

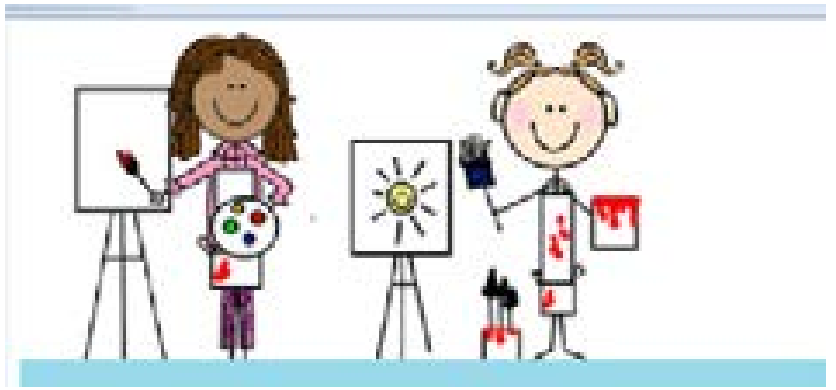

Fuente: Elaboración propia (2019)

h) De la investigación: El Aprendizaje Basado en Investigación (ABI) consiste en aplicar los pasos del método científico.

Imagen 36. Técnica de la investigación

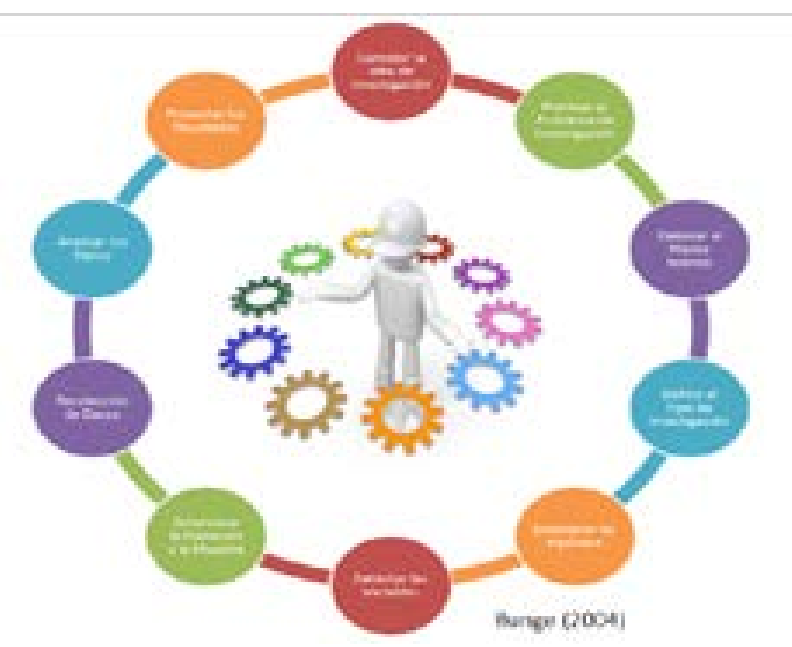

Fuente: Elaboración propia (2019) 
i) Del redescubrimiento: Es la manifestación heurística de nuevos conocimientos a través de la revelación del objeto mediante la indagación independiente.

Imagen 37. Técnica del redescubrimiento

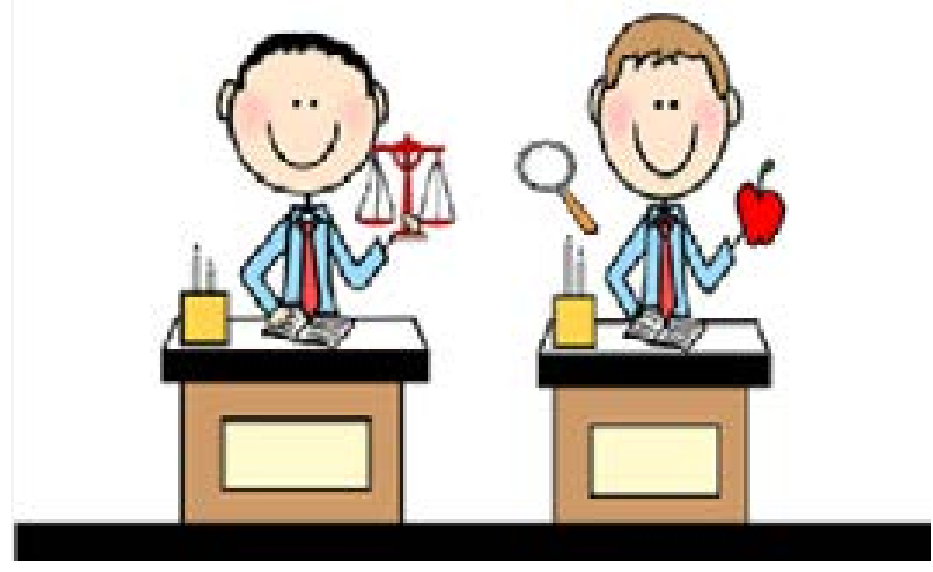

Fuente: Elaboración propia (2019)

j) De los círculos concéntricos: Es un círculo, donde se puede graficar esquemáticamente en forma secuencial con sentido a las agujas del reloj, la descripción de un tema, argumento o contenido conceptual desde lo particular a lo general.

Imagen 38. Técnica de los círculos concéntricos

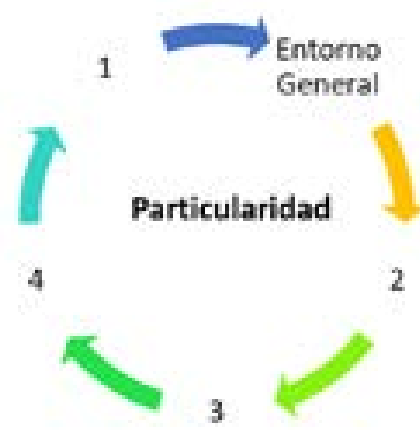

Fuente: Elaboración propia (2019)

k) De lectura: Consiste en realizar lectura secuenciales, intensivas, puntuales, de narración e interpretación y dictados, entre otras.

Imagen 39. Técnica de lectura

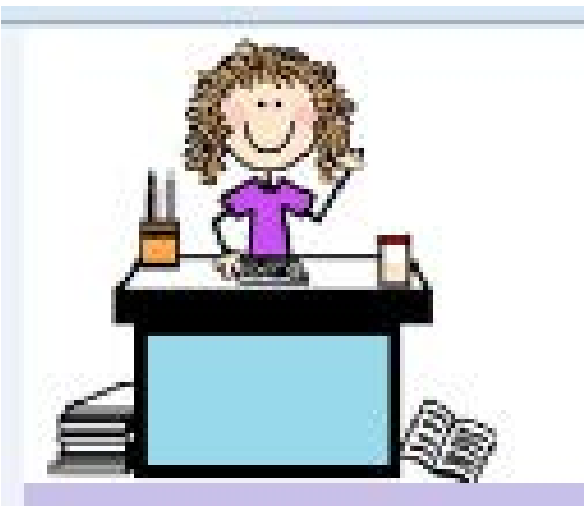

Fuente: Elaboración propia (2019 
I) De clases: Es el proceso organizativo del docente en cuyo espacio se realizan las distintas actividades planificadas.

Imagen 40. Técnica de clases

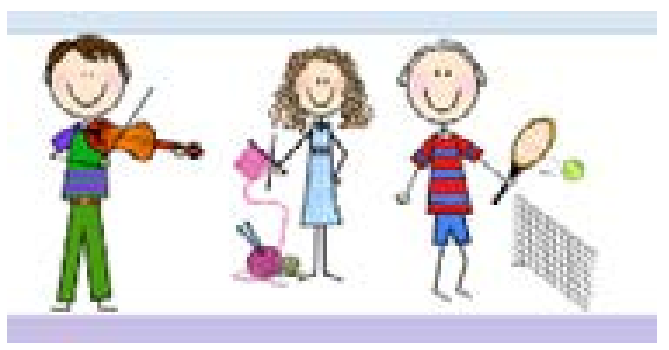

Fuente: Elaboración propia (2019

m) De tareas dirigidas: Es el repaso e integración de las lecciones vistas en el aula que consolida el conocimiento de una manera sistémica.

Imagen 41. De tareas dirigidas

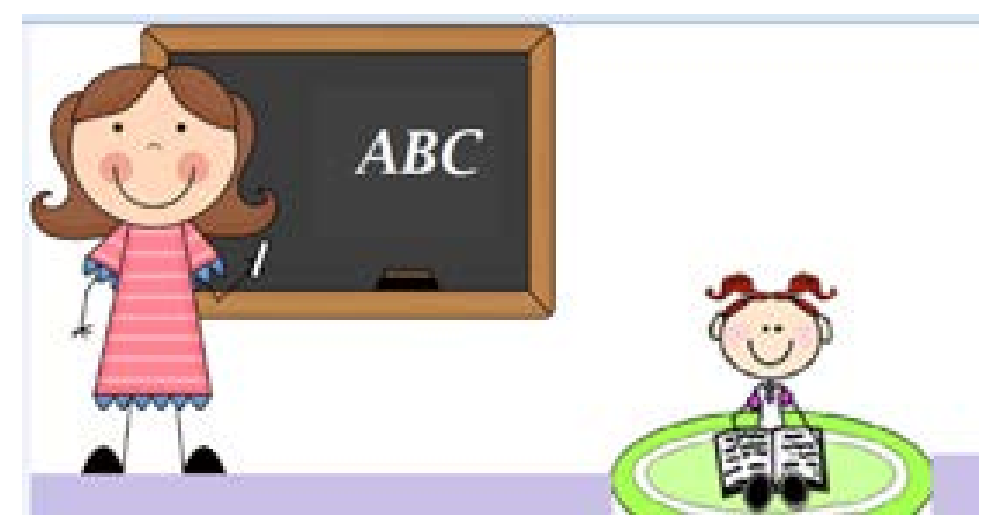

Fuente: Elaboración propia (2019 n) De enseñanza en grupo: Es el abordaje para el aprendizaje interactivo donde el estudiante se relaciona con otro y reconocer la importancia de la comunicación y de la dialogicidad.

\section{Imagen 42. Técnica de enseñanza en grupo}

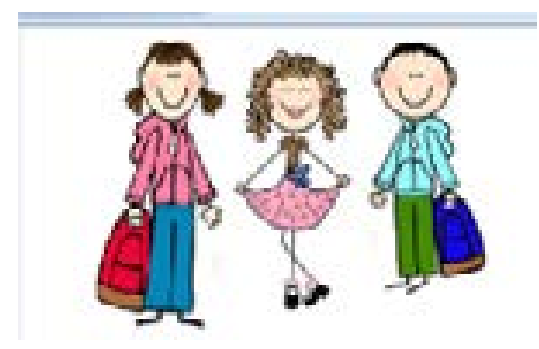

Fuente: Elaboración propia (2019)

ñ) De unidades didácticas: Es la interconexión de los elementos que se conjugan en los contenidos programáticos que puedan ser comprensibles para los estudiantes y aborde en su núcleo de desarrollo métodos adecuados.

Imagen 43. Técnica de unidades didácticas

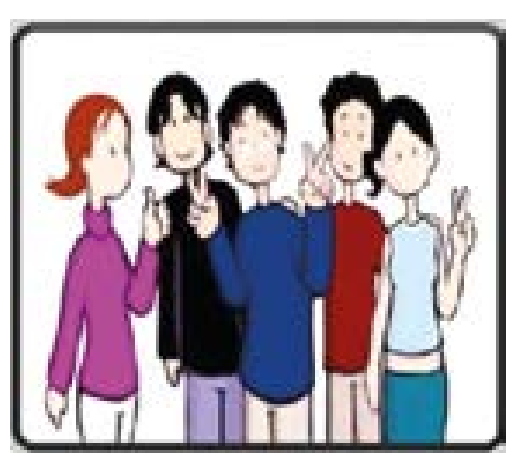

Fuente: Elaboración propia (2019 


\subsection{Técnicas para el trabajo en grupo:}

\subsubsection{Conferencia:}

Es una clase dialéctica en la cual se transmiten las novedades de las practicas científico-técnicas más actuales.

Imagen 44. Conferencia

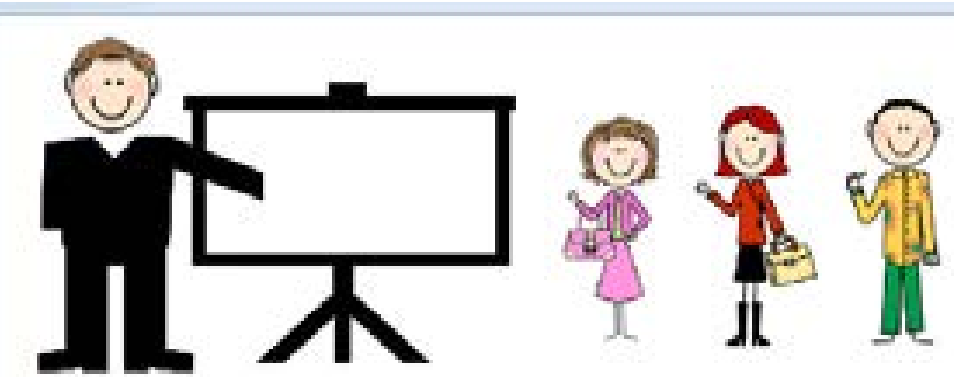

Fuente: Elaboración propia (2019

\subsubsection{Estudio dirigido:}

Es la dirección magistral del docente para que los estudiantes estudien un tema o unidad en particular, con el apoyo de textos, libros o guías.

\section{Imagen 45. Estudio dirigido}

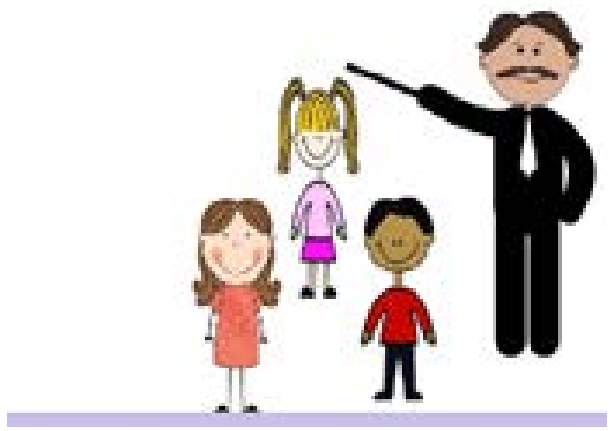

Fuente: Elaboración propia (2019

\subsubsection{Discusión en grupos:}

Es el espacio de socialización para que los grupos expongan argumentos en referencia a un tema para extraer una conclusión entre todos.

Imagen 46. Discusión en grupos

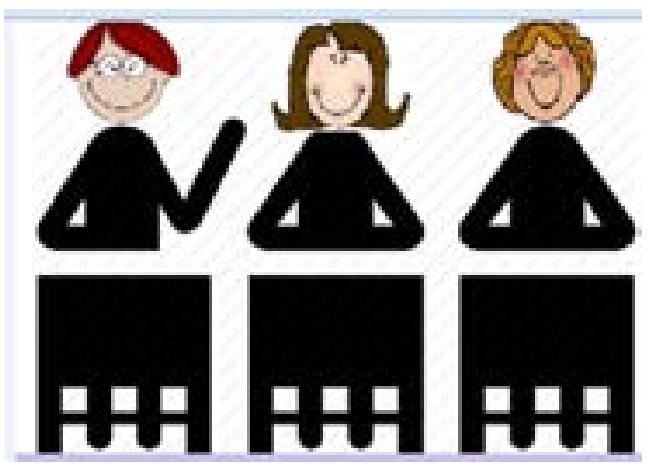

Fuente: Elaboración propia (2019 


\subsubsection{Simposio:}

Es un conversatorio en el que se da una charla para presentar una información concreta de un tema.

Imagen 47. Simposio

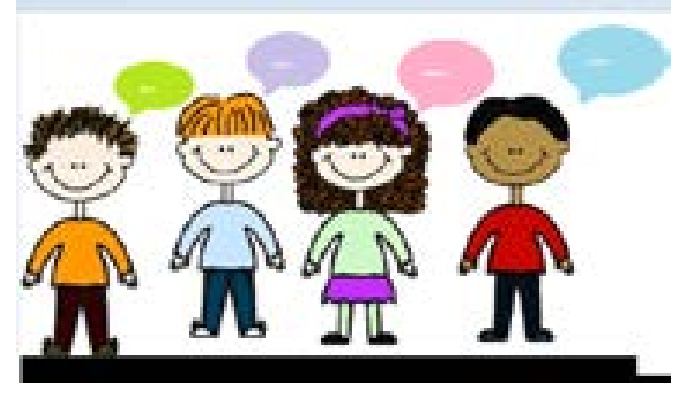

Fuente: Elaboración propia (2019

\subsubsection{Mesa redonda:}

Es la exposición sobre un tema por parte de un grupo de expertos que tiene puntos de vista diferentes.

Imagen 48. Mesa redonda

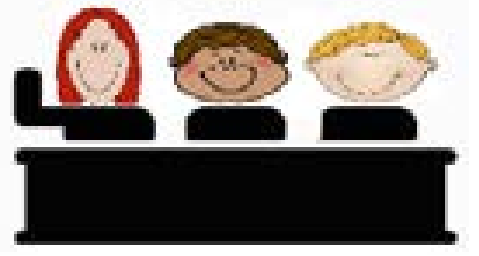

Fuente: Elaboración propia (2019

\subsubsection{Panel:}

Es la presentación de ideas sobre un tema ante un auditorio Imagen 49. Panel

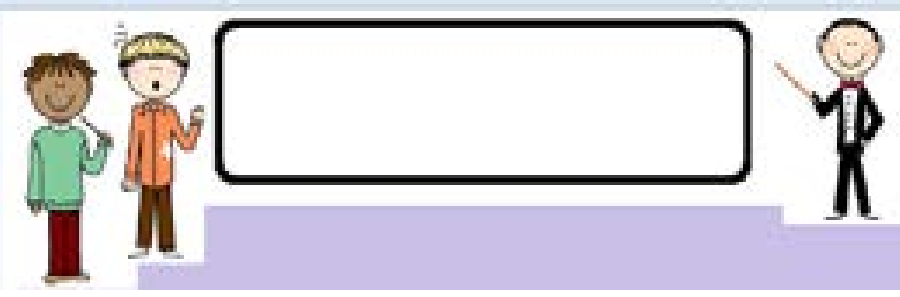

Fuente: Elaboración propia (2019

\subsubsection{Estudio de casos:}

Es la técnica adecuada para analizar un problema de una situación o persona en específico, se puede trabajar interdisciplinariamente.

Imagen 50. Estudio de casos

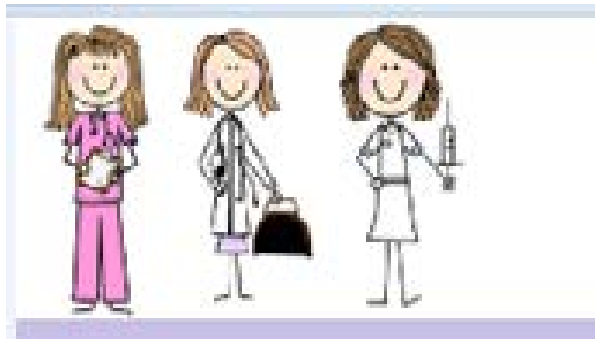

Fuente: Elaboración propia (2019 


\subsubsection{Seminario:}

Se destaca por ser una reunión de especialistas.

Imagen 51. Seminario

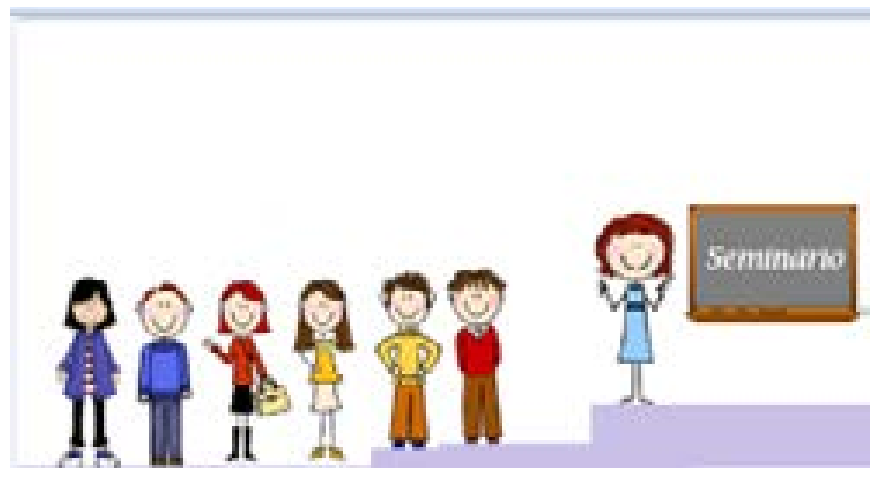

Fuente: Elaboración propia (2019

\subsubsection{Foro:}

Es un evento conducido por un coordinador donde los asistentes discuten un tema.

Imagen 52. Foro

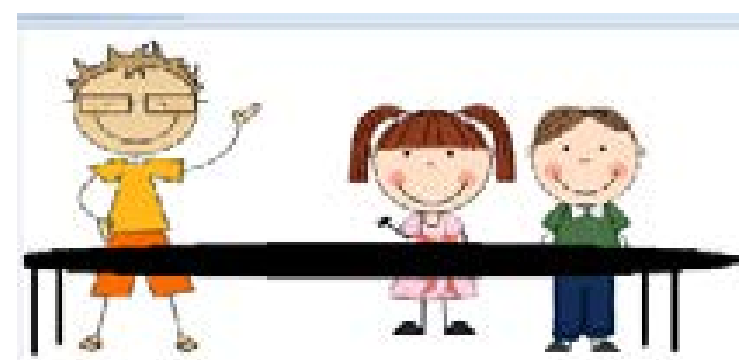

Fuente: Elaboración propia (2019

\subsubsection{Discusión guiada:}

Es un debate dirigido para estimular la participación de un grupo de personas sobre un tema para intercambiar ideas e información.

Imagen 53. Discusión guiada

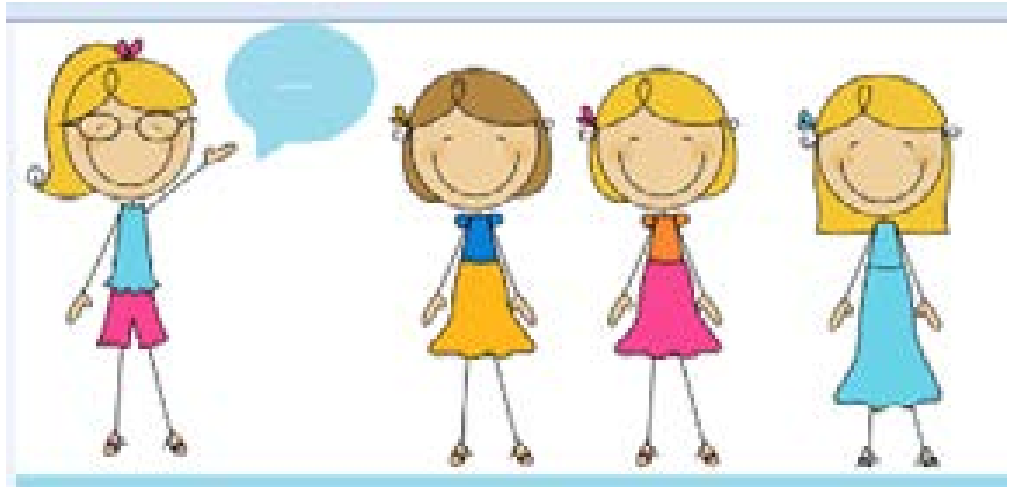

Fuente: Elaboración propia (2019

\subsubsection{Laboratorio:}

Es aquella clase que se da en espacios dispuestos para ello, en el que se giran instrucciones precisas a los participantes con la finalidad de poner en práctica los pasos del método científico mediante la experimentación. 
Imagen 54. Laboratorio

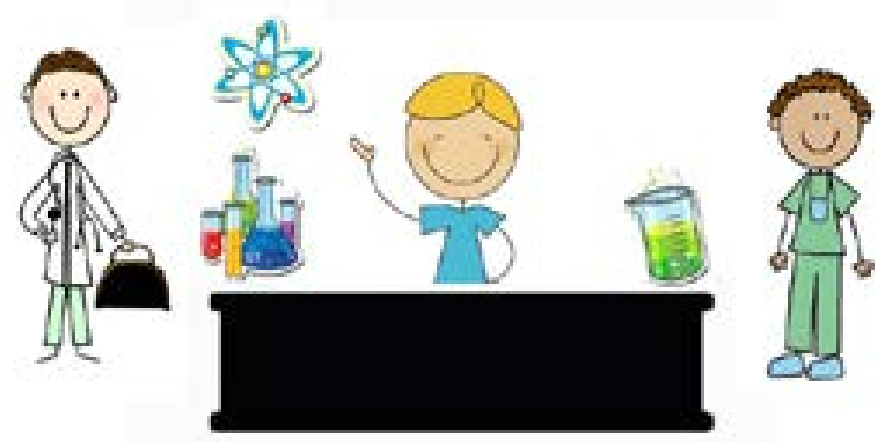

Fuente: Elaboración propia (2019

\subsubsection{Proyectos:}

Es una herramienta para resolver problemas que se plantean en torno a una situación.

Imagen 55. Proyectos

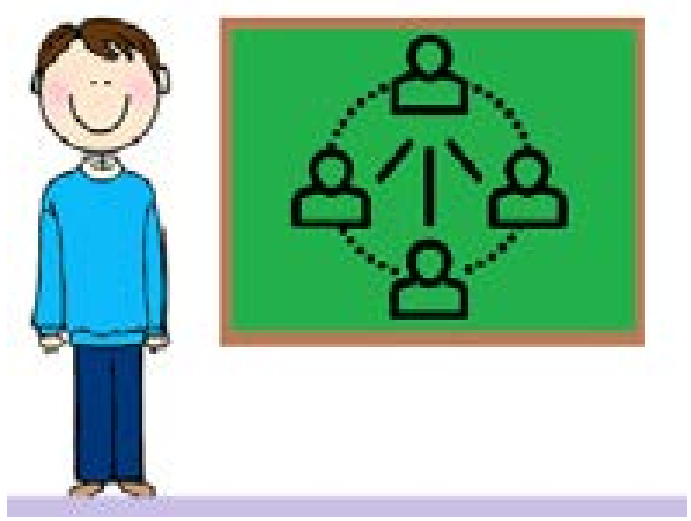

Fuente: Elaboración propia (2019

\subsubsection{Técnica Phillips 66:}

Se basa en dividir en grupos a los participantes para que discutan un tema y presentar al terminar sus conclusiones.

Imagen 56. Técnica Phillips 6.6

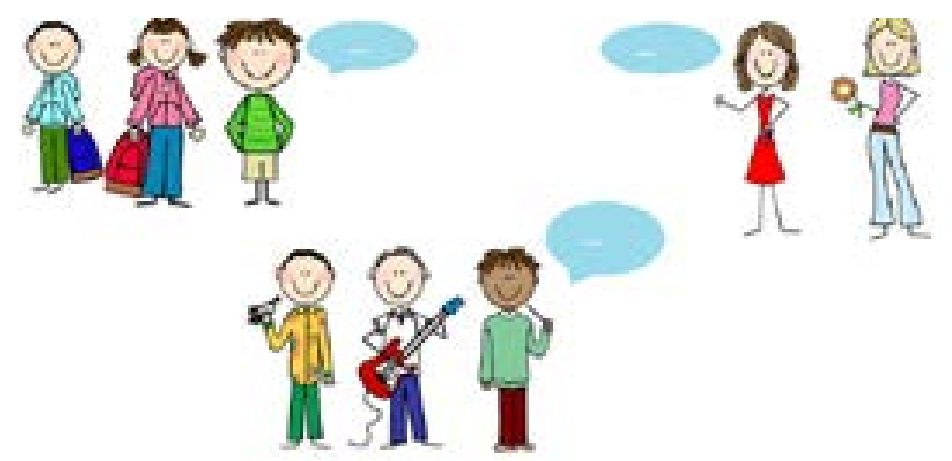

Fuente: Elaboración propia (2019

\subsubsection{Técnica de del cesto:}

Es una caja que contiene diverso material de diferentes tamaños, texturas y colores para incentivar los sentidos y las destrezas motrices y cognitivas. 
Imagen 57. Juego o test del cesto
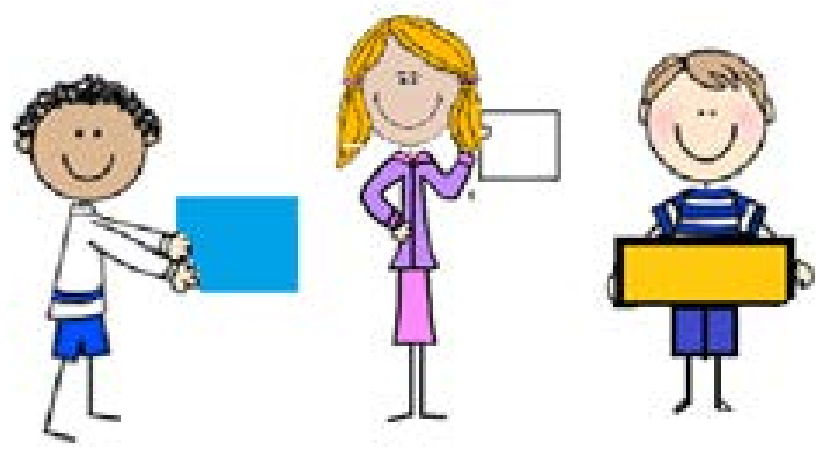

Fuente: Elaboración propia (2019

\subsubsection{Debate:}

Es una técnica donde se expone un tema de forma oral, cuyo desarrollo está dirigido por un moderador, un secretario y el público asistente.

Imagen 58. Debate

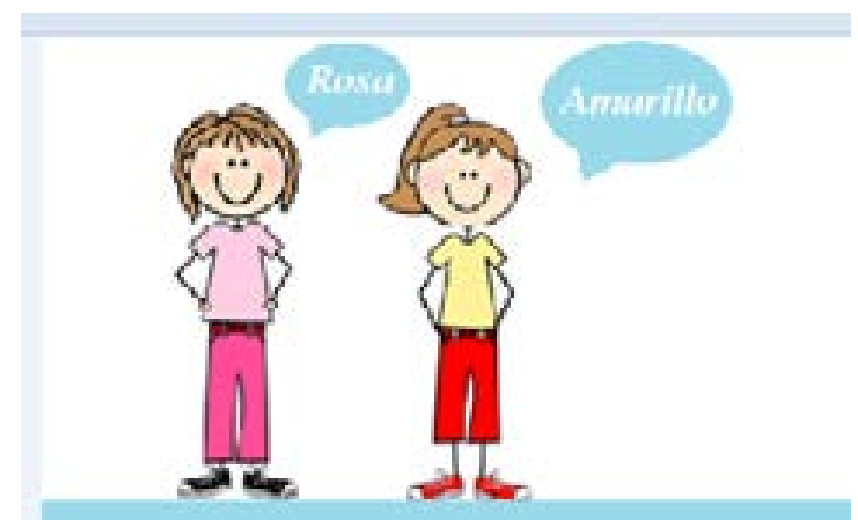

Fuente: Elaboración propia (2019

\subsubsection{Diálogos simultáneos:}

Son discusiones sincronizadas donde se divide a los participantes en grupos más pequeños para facilitar la discusión, con la finalidad de propiciar la intervención de todos los alumnos.

Imagen 59. Diálogos simultáneos

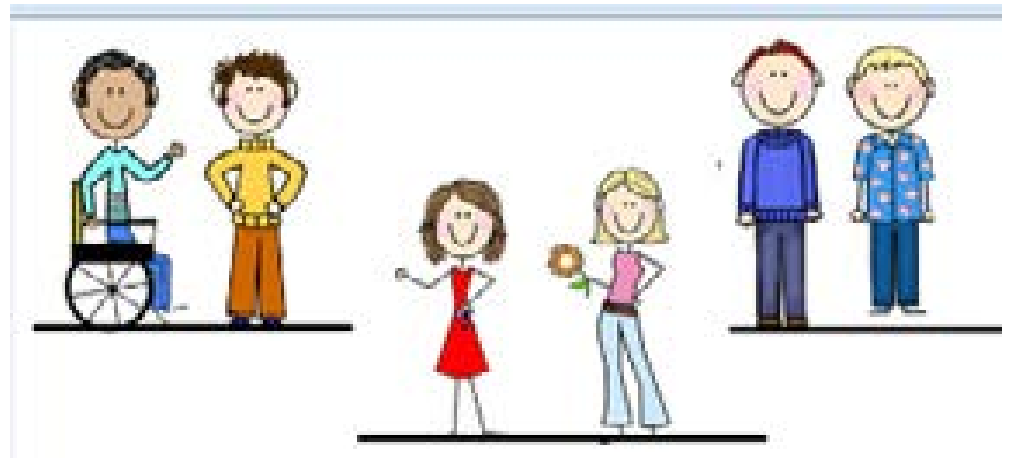

Fuente: Elaboración propia (2019

\subsubsection{Entrevista:}

Es el proceso dialógico e interactivo que se da entre dos personas para intercambiar información, donde uno de ellos ejerce el papel de entrevistador y el otro de informante cuyas preguntas se hacen a través de un interrogatorio. 
Imagen 60. Entrevista

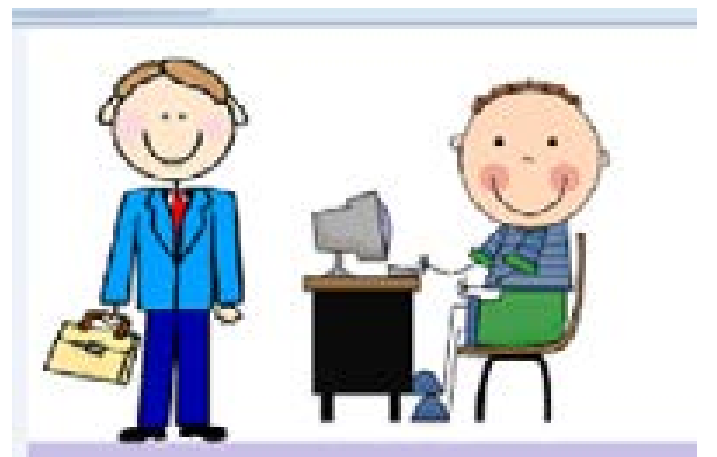

Fuente: Elaboración propia (2019

\subsubsection{Asamblea:}

Es la asistencia a una convocatoria previa donde la mesa directiva presenta un material informativo ante un auditorio.

Imagen 61. Asamblea

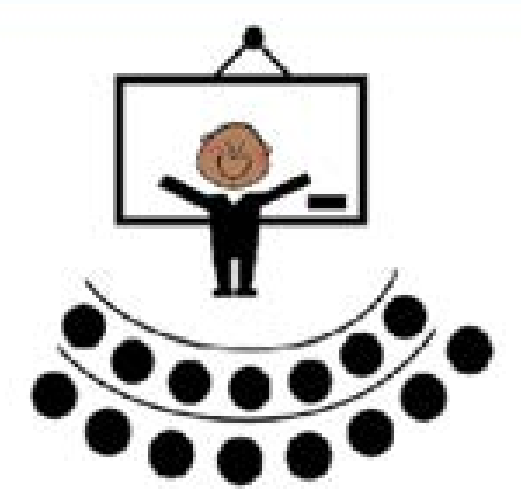

Fuente: Elaboración propia (2019

\subsubsection{Taller:}

Es la participación a un evento de un grupo pequeño de participantes donde se instruye sobre un oficio u ocupación.

Imagen 62. Taller
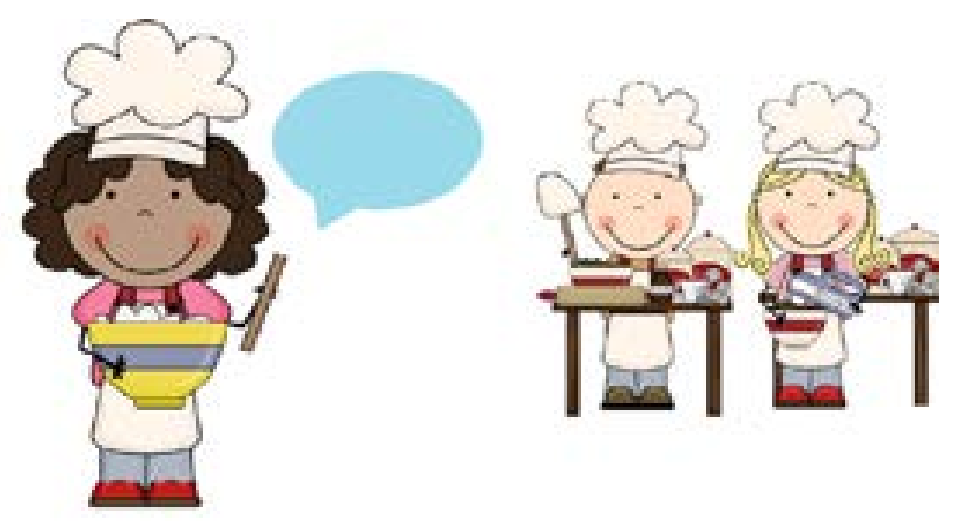

Fuente: Elaboración propia (2019

\subsubsection{Dinámica de Grupo:}

Consiste en dictar un conjunto de normas y procedimientos al colectivo de participantes la ejecución de un trabajo que amerite desarrollarla con una secuencia lógica. 
Imagen 63. Dinámica del trabajo grupal
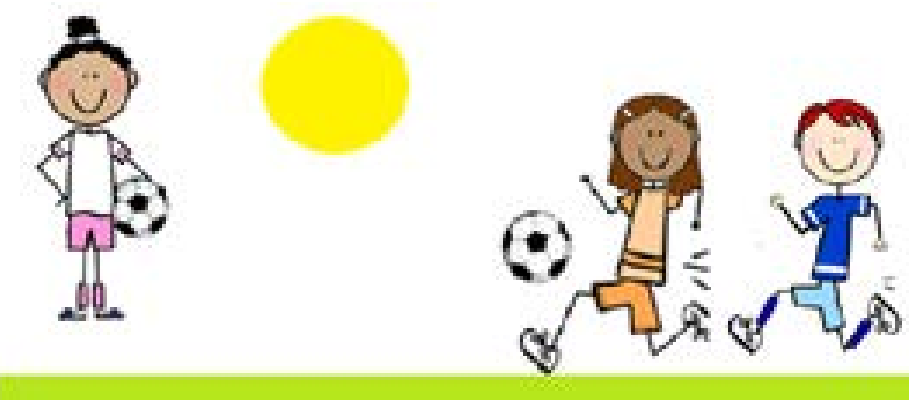

Fuente: Elaboración propia (2019

\subsection{Partiendo de los pilares educativos}

La construcción de técnicas de aprendizaje no puede estar aislada a los pilares que sostienen la educación, pues, son estas las bases que cimientan el compendio de cualidades que a juicio de Delors (1997:91) estimulan el desarrollo humano en todas las dimensiones al coadyuvar el trabajo educativo con un enfoque integrador, crítico y axiológico:

Para cumplir el conjunto de las misiones que les son propias, la educación debe estructurarse en torno a cuatro aprendizajes fundamentales que en el transcurso de la vida serán para cada persona, en cierto sentido, los pilares del conocimiento: aprender a conocer, es decir, adquirir los instrumentos de la comprensión; aprender a hacer, para poder influir sobre el propio entorno; aprender a vivir juntos, para participar y cooperar con los demás en todas las actividades humanas; por último, aprender a ser, un proceso fundamental que recoge elementos de los tres anteriores. Por supuesto, estas cuatro vías del saber convergen en una sola, ya que hay entre ellas múltiples puntos de contacto, coincidencia e intercambio.

En ese sentido, aprender a conocer incita a profundizar los conocimientos y formarse sobre la base científica, técnica y tecnológica inmersa en valores humanistas con pertinencia social y de manera integral para desarrollar su superación personal y profesional con la finalidad de optimizar su desempeño en el ambiente educativo.

$\mathrm{Al}$ referirse al pilar Aprender a hacer, sugiere que el docente debe formarse para adquirir competencias que le permitan desarrollarse en su quehacer pedagógico y poder así enfrentar todas las situaciones diversas que se presenta en un ambiente de aprendizaje con el objetivo de afianzar y enriquecer su experiencia educativa.

Con respeto a lo que define el pilar Aprender a vivir juntos, propone que el docente sea capaz de comprender al otro, a su compañero, a sus estudiantes, ser más empático para flexibilizar la percepción de las cosas, convivir armoniosamente, fomentar el valor de la paz, saber escuchar, comunicarse asertivamente y deliberar temas sin discusiones estériles.

Finalmente, el pilar Aprender a ser, denota la responsabilidad y el compromiso que todo docente debe poseer en cuanto a su profesión y frente a sus estudiantes, dado que el mismo representa un modelo a seguir para futuras generaciones en su rol formador y mediador del aprendizaje que facilita las técnicas de cognición. 
Imagen 63. Pilares de la Educación.

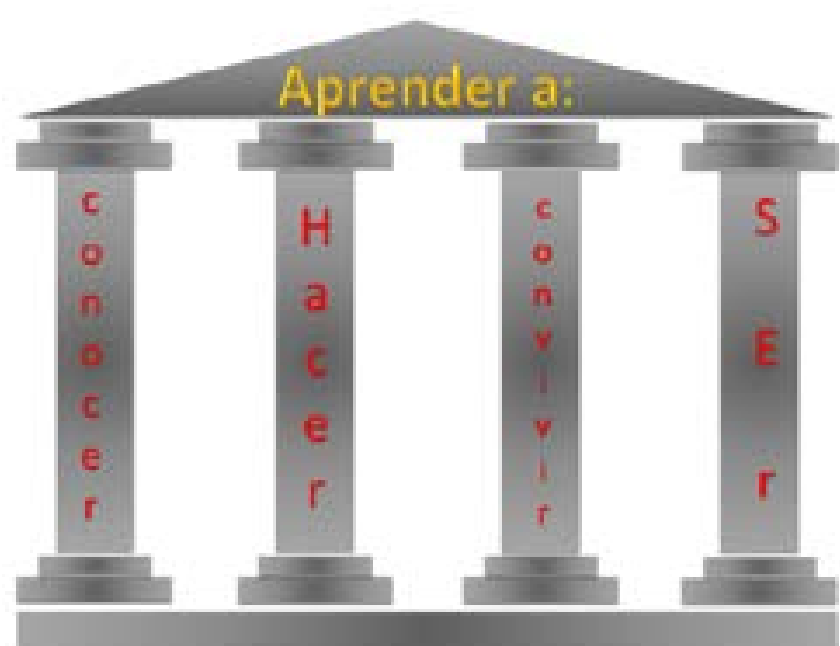

Fuente: Elaboración propia a partir de Delors (1997)

\subsection{Organización de técnicas pedagógicas para desarrollar} destrezas educativas

Cuadro 1.Técnicas pedagógicas para desarrollar destrezas educativas

\begin{tabular}{|c|c|c|}
\hline $\begin{array}{c}\text { AREA DE } \\
\text { APRENDIZAJE }\end{array}$ & TECNICAS & DESTREZA \\
\hline $\begin{array}{l}\text { Educación cultu- } \\
\text { ral y artística }\end{array}$ & $\begin{array}{ll}\text { - } & \text { Obras de Teatro } \\
\text { - } & \text { Talleres de música } \\
\text { - } & \text { Danzas }\end{array}$ & $\begin{array}{l}\checkmark \checkmark \text { Cooperación en } \\
\text { la formación integral } \\
\text { del individuo, } \\
\checkmark \quad \text { Manifestación } \\
\text { espontánea de la } \\
\text { personalidad, } \\
\checkmark \quad \text { Desarrolla el } \\
\text { sentido estético a } \\
\text { través de la com- } \\
\text { prensión de imáge- } \\
\text { nes plásticas. } \\
\checkmark \quad \text { Libertad y } \\
\text { espontaneidad para } \\
\text { manifestarse creativa } \\
\text { y originalmente. Ca- } \\
\text { pacidad de expresión } \\
\text { e imaginación }\end{array}$ \\
\hline $\begin{array}{c}\text { Educación } \\
\text { Física }\end{array}$ & $\begin{array}{ll}\text { - } & \text { Desplazamientos } \\
\text { - } & \text { Saltos } \\
\text { - } & \text { Giros } \\
\text { - } & \text { Lanzamientos } \\
\text { - } & \text { Recogidas y Recep- } \\
\text { ciones }\end{array}$ & $\begin{array}{l}\checkmark \quad \text { Habilidad } \\
\text { Motriz } \\
\checkmark \quad \text { Destrezas Mo- } \\
\text { trices }\end{array}$ \\
\hline $\begin{array}{l}\text { Ciencias } \\
\text { naturales }\end{array}$ & $\begin{array}{l}\text { - } \quad \text { Exposición } \\
\text { - } \quad \text { Trabajo Grupal } \\
\text { - } \quad \text { Pruebas de labora- } \\
\text { torio } \\
\text { - } \quad \text { Trabajo de Campo } \\
\text { - } \quad \text { Practica guiada }\end{array}$ & $\begin{array}{ll}\checkmark & \text { Observación } \\
\checkmark & \text { clasificación } \\
\text { inferencia } \\
\checkmark & \text { comunicación } \\
\checkmark & \text { medición } \\
\checkmark & \text { predicción }\end{array}$ \\
\hline
\end{tabular}




\begin{tabular}{|c|c|c|}
\hline $\begin{array}{l}\text { Ciencias } \\
\text { sociales }\end{array}$ & $\begin{array}{l}\text { - Clase expositiva } \\
\text { - Lectura continua, } \\
\text { interpretación y sistema- } \\
\text { tización } \\
\text { - Investigación y el } \\
\text { discernimiento crítico } \\
\text { - Aplicación creativa } \\
\text { de conocimientos e infor- } \\
\text { maciones. Foros } \\
\text { - Producción de ideas. } \\
\text { Ensayos. } \\
\text { - Línea del tiempo }\end{array}$ & $\begin{array}{l}\checkmark \quad \text { De ubicación } \\
\text { espacial } \\
\checkmark \quad \text { La ubicación } \\
\text { temporal } \\
\checkmark \quad \text { La interrelación } \\
\text { social }\end{array}$ \\
\hline $\begin{array}{l}\text { Lengua y } \\
\text { literatura }\end{array}$ & $\begin{array}{l}\text { - Producción escrita } \\
\text { - Dictado } \\
\text { - Lectura e interpreta- } \\
\text { ción de textos }\end{array}$ & $\begin{array}{l}\checkmark \quad \text { Producir efi- } \\
\text { cazmente mensajes } \\
\text { lingüísticos y no } \\
\text { lingǘsticos. } \\
\checkmark \quad \text { Comprender } \\
\text { textos escolares } \\
\checkmark \quad \text { Escribir multi- } \\
\text { plicidad de textos } \\
\checkmark \quad \text { Participar en } \\
\text { producciones lite- } \\
\text { rarias }\end{array}$ \\
\hline Matemática & $\begin{array}{l}\text { - } \quad \text { Practica guiada } \\
\text { - } \quad \text { Visualización de } \\
\text { graficas } \\
\text { - } \quad \text { Memorización } \\
\text { - } \quad \text { Ejercicios indivi- } \\
\text { duales }\end{array}$ & $\begin{array}{l}\checkmark \quad \text { Conteo y valor } \\
\text { numérico } \\
\checkmark \quad \text { Operaciones y } \\
\text { pensamiento alge- } \\
\text { braico } \\
\checkmark \quad \text { Números y } \\
\text { operaciones sobre la } \\
\text { base de } 10 \\
\checkmark \quad \text { Mediciones y } \\
\text { datos } \\
\checkmark \quad \text { Geometría }\end{array}$ \\
\hline
\end{tabular}

\begin{tabular}{|c|l|ll|}
\hline \multirow{*}{*}{ Lengua } & • Conversatorios & & \\
& - Dictado & & \\
extranjera & - Uso del Diccionario & $\checkmark$ & Comstrucción de ora- \\
& $\begin{array}{l}\text { ciones y textos escritos } \\
\text { - Repetición memo- }\end{array}$ & $\checkmark$ & Lingüística \\
& rística, & \\
\hline
\end{tabular}

Fuente: Elaboración propia

\subsection{Hacia la construcción de un modelo instruccional que permita la aprehensión de destrezas}

Con un enfoque integrador se sistematiza en la siguiente representación gráfica una propuesta de modelo que simplifica la aprehensión del Desarrollo cognitivo de las destrezas en tres fases:

En la primera fase, se realiza el diagnóstico para conocer las brechas y necesidades educacionales partiendo de las particularidades individuales de los estudiantes y de los estilos de aprendizaje para saber cómo abordar las situaciones encontradas con atención a la diversidad para generar los planes y los materiales efectivos para la instrucción.

En la fase dos, el modelo visualiza propiamente el acto pedagógico donde se definen los recursos se determinan las técnicas apropiadas en concordancia a los hallazgos encontradas en la fase anterior, para luego hacer la planificación con base a las metas instruccionales que incluye el diseño curricular de atención a los estudiantes.

El propósito de la tercera fase es discernir y observar el desarrollo de las destrezas y habilidades que potencian el conocimiento y la aprehensión práctica con la aplicación de las 
técnicas adecuadas en un profundo análisis que comprende la evaluación de la efectividad de las estrategias que se dedujeron mediante un método profundo de estudio.

Imagen. Modelo de Aprehensión del Desarrollo cognitivo de las destrezas

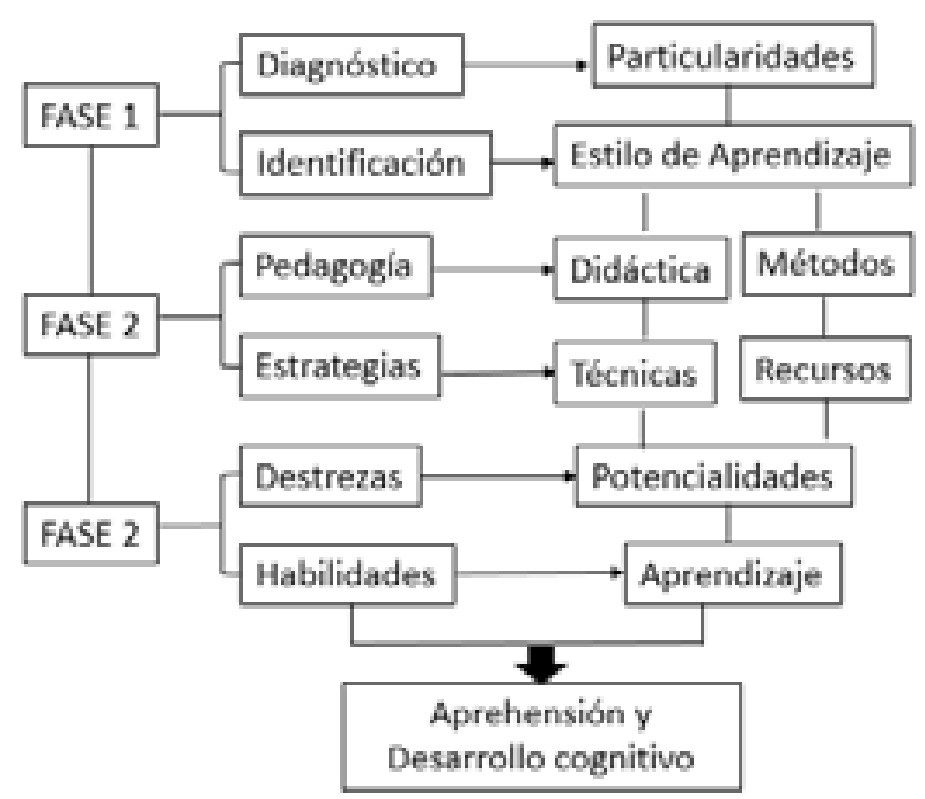

Fuente: Elaboración propia

\section{CONCLUSIONES}

El ejercicio de reflexión crítica realizado en la elaboración de este trabajo, permite a los autores proponer un entramado de opciones educativas que den cuenta de las técnicas adecuadas a la pertinencia de acción pedagógica en procura del desarrollo cognitivo del estudiante, precursora de modelos prácticos, sencillos y novedosos que tributen al afianzamiento del aprendizaje efectivo.

Por tanto, a juicio de los autores, el aporte del presente trabajo debe a incentivar la promoción de la conducción a la autogestión del docente para la aplicación de técnicas concernientes al desarrollo de destrezas de aprendizaje en todos sus niveles y condiciones cognitivas, dado que se impone la necesidad de abordar las estrategias desde su base nucleico para determinar si es útil y eficiente.

Otro aspecto que ilustra el libro, está asociada a la motivación y la auto regulación del individuo con la intervención del docente en la mediación de los procesos de desaprendizaje para el reaprendizaje al ofrecer todas las competencias obtenidas de la formación, experiencia y vocación, al extrapolar la idea que sustentas los pilares de la educación.

Fundamentalmente, se requiere que el docente haga suyo este libro, transforme y adecue si es necesario el entorno espacial de la capacitación del estudiante para aprender, reaprender y desaprender, como opción prioritaria que le permita adaptarse a un futuro transformado desde su propia perspectiva, visión, misión, metas y aspectos ontoepistemicos y axiológicos. 


\section{BIBLIOGRAFÍA}

Abbagnano, N. (1992). Historia de la pedagogía Autores: Visalberghi, A. Editorial: Fondo de Cultura Económica Novena reimpresión, 1992 Tema: Pedagogía, Educación - Historia ISBN.: 84-375-0005-2 Ríos, C. P. (2006). Psicología. La aventura de conocernos. Venezuela. Caracas. Universidad Pedagógica Experimental Libertador. Vice-rectorado de Investigación y Postgrado: Línea Gráfica 67, C.A.

Aliendres, N. (2012). Competencias del docente para el logro de una educación de calidad en el instituto universitario de tecnología de Puerto Cabello. Universidad de Carabobo, Ffacultad de ciencias de la educación dirección de postgrado maestría en gerencia avanzada en educación. Tesis,

Álvarez, V. (1984). Diagnostico Pedagógico. Sevilla: Alvar.

Arriaga, M. (2015). El diagnóstico educativo, una importante herramienta para elevar la calidad de la educación en manos de los docentes Atenas, vol. 3, núm. 31, julio-septiembre, pp. 63-74 Universidad de Matanzas Camilo Cienfuegos Matanzas, Cuba

Ausubel, D. P. (1978). Psicología educativa. Un punto de vista cognoscitivo. Ed. Trillas. México.

Brito, L. (2008). Educación popular, cultura e identidad desde la perspectiva de Paulo Freire. En publicación: Paulo Freire. Contribuciones para la pedagogía. Moacir Godotti, Margarita 
Victoria Gómez, Jasón Mafra, Anderson Fernandes de Alencar (compiladores). CLACSO, Consejo Latinoamericano de Ciencias Sociales, Buenos Aires. Enero 2008. ISBN 978-987-1183$81-4$

Buisán y Marín (2001), Cómo realizar un Diagnóstico Pedagógico. México: Alfa Omega

CAST (Center for Applied Special Technology) (2011). Universal Design for Learning guidelines version 2.0. Wakefield, MA: Author. Traducción al español versión 2.0 (2013): Alba Pastor, C., Sánchez Hípola, P., Sánchez Serrano, J. M. y Zubillaga del Río, A. Pautas sobre el Diseño Universal para el Aprendizaje (DUA).

Corominas, E. (2001). Competencias genéricas en la formación universitaria Nro. 325. Madrid.

Corral, R, (2001). El concepto de zona de desarrollo próximo: una interpretación. Revista cubana de psicología Vol. 18, No. 1. Facultad de Psicología, Universidad de La Habana.

Cruz y Miranda (2009). Universidad Autónoma “Tomás Frías". Maestría en ciencias de la educación. Módulo Filosofía y Sociología de la Educación Material Básico Compilado

Del Granado Cosio, Teresa. Apuntes que señalan una nueva concepción educativa. En publicación: Paulo Freire. Contribuciones para la pedagogía. Moacir Godotti, Margarita Victoria Gómez, Jason Mafra, Anderson Fernandes de Alencar (com- piladores). CLACSO, Consejo Latinoamericano de Ciencias Sociales, Buenos Aires. Enero 2008. ISBN 978-987-1183-81-4

Delors J. (1997). La educación encierra un tesoro. Informe a la UNESCO de la comisión internacional sobre la educación para el siglo XXI. Correo de la UNESCO. Ediciones UNESCO. México.

Diccionario de la Real Academia Española, disponible en: https://dle.rae.es/?id=ZIkyMDs

Diccionario etimológico. Disponible en: http://etimologias. dechile.net/?pedagogi.a

Felder, R., y Silverman, L (1988). Estilos de aprendizaje y de enseñanza en la educación de ingeniería [Versión electrónica]. Ing. Educación, 78 (7), 674-68

Fernández, A. (2017). El diseño curricular. La práctica curricular y la evaluación curricular (Adaptaciones de propuestas de varios autores)

Fonseca, H. \& Bencomo, M.N. (2011). Teorías del aprendizaje y modelos educativos: revisión histórica. Salud Arte y Cuidado, 4(1), 71-93.

Freire, Paulo 1979 (1971) “Astutos e inocentes” en Concientização: teoría y prática da libertação. Uma introdução ao pensamento de Paulo Freire (San Pablo: Cortez \& Moraes). Revista ORBIS / Ciencias Humanas 
Fulatt O. (1992). Conceptos básicos en la pedagogía. Ediciones CEAC Perú 164-08020. Barcelona, España Salud Arte y Cuidado Julio -Diciembre 2011; 4(Suplemento 1): 71-93 La Revista de Enfermería y Ciencias de la Salud Fecha de recepción: 19/10/2011 Fecha de aprobación: 15/12/2011 SAC 71

García, L., Meschman, L, Garua, A., González, D. y Maiorana, S. (2012). La intervención de los tutores de prácticas en la promoción de competencias didácticas, evaluativas y metacognitivas en los dispositivos de formación de profesores en psicología. V Congreso Internacional de Investigación y Práctica Profesional en Psicología. XX Jornada

García, V. (1995). Diagnóstico, evaluación y toma de decisiones. España: Ediciones Rialp S.A.

Garnier, J. (2008). La arquitectura de la nueva sensibilidad. Universidad de la Salle. Doctorado en Educación.

Garza, E. (2000). Instituto Tecnológico y de Estudios Superiores de Monterrey 2501, Col. Tecnológico, Monterrey, N.L. C.P. 64849.

Gobierno de Chile. Ministerio de Educación (2009). Orientaciones para la planificación de la enseñanza. Recuperado de file://C:/Users/Raquel\%20Lamus/Downloads/planificacion_ ensenanza_chile\%20(1).pdf

Granados, P. (2003). Diagnóstico pedagógico. Madrid: Dikisón.
Grinder y Bandler (1975). La estructura de la magia II. PNL. Vol. 2. Traducción: Elena Olivos \& Ataliva Amengual \& Francisco Huneeus Editor digital: diegoan e Pub base r1.1

Guerrero, W., y Borjas, F, (2006). Gestión del Docente y la Ejecución de los Proyectos Pedagógicos de Aula en Educación Básica. Dep. Legal: ppx 200502zu1935 / ISSN: 1856-1594 / Directorio LATINDEX: 14.510 / Directorio REVENCYT: RVO004 Directorio de Revistas especializadas en Comunicación del Portal de la Comunicación InCom-UAB Directorio CLASE / Directorio REDALyC

Hermann, N. (1991). La Creatividad Cerebro. El diario de comportamiento creativo.

Joyce, B. Y Weill, N. (1985). Modelos de Enseñanza. New Jersey, USA. Prentice Hall, Inc. Traducción de Ricardo Sánchez. Editorial Anaya

Kant, I. (2009). SOBRE PEDAGOGÍA Traducción y nota preliminar por Oscar Caeiro. ISBN: 978-987-1432-25-7 Queda hecho el depósito que marca la ley 11.723 Impreso en Argentina Editorial Universidad Nacional de Córdoba Encuentro Grupo Editor

Kolb, B. y Taylor, L. (1990). Neocortical substrates of emotional behavior. En N.L. Stein, B. Leventhal y T. Trabasso (eds.): Psychological and Biological Approaches to Emotion (pp. 115-144). Hillsdale, NJ: Erlbaum 
Lamus, T. (2011) Formación y desarrollo de valores robinsonianos en los estudiantes del programa nacional de formación de educadores y educadoras de la Universidad Bolivariana de Venezuela. Tesis doctoral IPLAC-UBV

Losada, A. Montaña, A, y Moreno, H. (2003). Método, Técnica y Estrategia de enseñanza y aprendizaje. Editorial SEM, ISBN 958-97195-4-6, Colombia.

MacLean, P. (1967). The triune brain evolution: role in paleocerebral functions. New York, EEUU: Ed. PlenunPress.

Mendo, J. (2006). El currículo como construcción social. Entre la utopía y la vida. Fondo Editorial del Pedagógico. Lima.

Morín E. (2000). Los siete saberes necesarios a la educación del futuro. Caracas: Iesal-Unesco; Faces-Cipost-UCV.

Nassif, Ricardo (1977). Pedagogía general. Cincel: Madrid

Navarro, I. (2011). El trabajo colaborativo como estrategia para el desarrollo de competencias profesionales. En Álvarez Teruel, J. D. y Gómez Lucas, M. C. (comps.) La autoevaluación, clave en el proceso de instrucción. El trabajo colaborativo como indicador de la calidad del EEES. Alcoi: Marfil.

Panamá, G. d. (2005). Gobierno de Panamá, 2005. Documentos desarrollados para capacitación profesional como parte del Plan Nacional de Inclusión Educativa en 65 centros pilotos del país
Pérez y Sacristán (1992). Comprender y transformar la enseñanza. Editorial Morata. Madrid.

Piaget, J. (1948). Psicología de la inteligencia. Buenos Aires: Psique

Piaget, J. (1967/1971). Biologie et connaissance: Essai sur les relations entre les régulations organiques et les processus cognitifs. Gallimard: Paris - Biology and Knowledge. Chicago University Press; y Edinburgh University Press.

Piaget, J. (1970). Piaget's theory. En P. H. Mussen (Comp.), Carmichael's manual of child psychology. Vol 2. Nueva York: Wiley.

Ríos, C. P. (2006). Psicología. La aventura de conocernos. Venezuela. Caracas. Universidad Pedagógica Experimental científica. Venezuela. Caracas: EPISTEME, C.A

Romea, C. (2001). Los nuevos paradigmas para los procesos de enseñanza/aprendizaje en la sociedad del conocimiento EN E/LE MAGRIBERIA No 4 - 2011 Universitat de Barcelona.

Sobrado, Cauce \& Rial (2002). Las habilidades de aprendizaje y estudio en la educación secundaria: estrategias orientadoras de mejora. Universidad de Santiago de Compostela. Tendencias Pedagógicas 7

Sperry, R (1961). Cerebral organization and behavior. The split brain in many respect like two separates brain, provided 
new research possibilities. Reprinted from Science, June 2, Vol. 133, No. 3466, pages 1749-1757

Tünnermann Bernheim, C. (ed.). (2008): "La educación superior en América Latina y el Caribe: diez años después de la Conferencia Mundial de 1998". Editorial Javeria, Colombia

Tyler, R. W. (1949). Basic principles of curriculum and instruction. Chicago: University of Chicago Press

UNESCO. (1997) 50 años en pro de la Educación. Paris, Francia

Vásquez, F. (2010) Investigación educativa; Estrategias educativas; Didáctica; Educación; Docencia; Enseñanza; Integración escolar; Colombia; América del Sur; Bogotá D.C.

Vygotsky, L. (1934-1993) "Pensamiento y Lenguaje”. En Obras escogidas. TII Madrid: Visor 